Revista Española de Antropología Americana ISSN: 0556-6533

https://doi.org/10.5209/reaa.66530

\title{
Formatos y motivos visuales como reflejos de pactos y matrimonios en el discurso monumental de los Kanu'l y sus aliados en el Clásico Tardío
}

\author{
Verónica A. Vázquez López ${ }^{1}$
}

Recibido: 5 de marzo de 2019 / Aceptado: 3 de junio 2019

Resumen. La evidencia epigráfica, iconográfica y arqueológica muestra el desarrollo de estrategias sociopolíticas como matrimonios y pactos entre la dinastía Kanu'l y sus aliados, particularmente entre los siglos VII y VIII en el área maya. Mediante estas estrategias se creó un sistema sociopolítico estable y duradero que favoreció a la hegemonía Kanu'l, en el que los participantes gozaron de los logros de la dinastía y de la participación en una red social, económica y política. En este trabajo me centro en la descripción e interpretación de algunos rasgos formales y motivos icónicos que muestran distribuciones regionales significativas. Dichos patrones, en conjunto con los datos epigráficos y arqueológicos, nos permiten definir algunas de las estrategias sociopolíticas desarrolladas y empleadas por los Kanu'l durante el Clásico Tardío. Distintos tipos de afiliación fueron representados de diferentes maneras en el registro gráfico, el cual revela redes a nivel intersitio y sus efectos en el paisaje político.

Palabras clave: análisis iconográfico, epigráfico y arqueológico; estrategias sociopolíticas; mayas del periodo Clásico Tardío; dinastía Kanu'l y Calakmul.

\section{[en] Visual Formats and Motifs as References of Pacts and Marriages in the Monumental Discourse of the Kanu'l Dynasty and its Allies during the Late Classic Period}

\begin{abstract}
Epigraphic, iconographic and archaeological evidence shows the development of strategies for sociopolitical reproduction through marital alliances and pacts between the Kanu'l dynasty and its allies, especially during the $6^{\text {th }}$ and $7^{\text {th }}$ century AD in the Maya region. This kind of strategies of social cohesion pursued the creation of a system of stable and durable sociopolitical relations that supported the development of the Kanu'l hegemony. Here, I focus on the description and interpretation of some formal traits and iconic motives that expose significant patterns of regional distribution. These patterns, together with the epigraphic and archaeological data, allow us to define some of the mentioned sociopolitical strategies. Different kinds of affiliations were represented in different ways in the graphic record, revealing a network among several sites and its effects on the political landscape.
\end{abstract}

Keywords: iconographic, epigraphic and archaeological analysis; sociopolitical strategies; Late Classic Maya society; Kanu'l dynasty and Calakmul.

Sumario: 1. Introducción. 2. Los programas visuales de los Kanu'l. 3. Discusión. 4. Referencias.

\footnotetext{
1 Investigadora de posdoctorado, Departamento de Antropología y Arqueología, Universidad de Calgary, Canadá. Becaria de posdoctorado CONACyT, estancias en el extranjero. vevalo21@yahoo.com
} 
Cómo citar: Vázquez López, Verónica A. 2019. «Formatos y motivos visuales como reflejos de pactos y matrimonios en el discurso monumental de los Kanu'l y sus aliados en el Clásico Tardío». Revista Española de Antropología Americana 49: 239-271.

\section{Introducción}

Los avances en el análisis epigráfico de expresiones jerárquicas han sido de gran valor en el entendimiento de la dinámica política maya del Clásico (250-900 d.C.). En la última década, nuevos hallazgos y perspectivas teóricas han abierto este campo de investigación a distintos niveles de análisis, desde la configuración de la corte real (ver Jackson 2005, 2013) hasta la interacción entre las unidades sociales empoderadas dentro de un sistema hegemónico a nivel regional (ver Martin y Grube 1995, 2008). En este contexto, tanto el dato epigráfico como el iconográfico y el arqueológico proporcionan información de gran valor, en particular cuando los cruzamos.

A lo largo del periodo Clásico, la dinastía Kanu'l construyó una amplia red hegemónica que incluyó a varias entidades sociopolíticas. Un sistema complejo de este tipo requirió de una serie de estrategias para estabilizar los vínculos entre las distintas casas reales, que incluía matrimonios y otros tipos de pactos. La evidencia también muestra varios grados de integración de las distintas unidades sociales, relacionadas con la distancia física de la sede de poder, además de otros factores. Las alianzas e interacciones sociopolíticas están bien atestiguadas en el registro epigráfico, en particular en los siglos VII y VIII. No obstante, la epigrafía no es la única fuente relevante de información, ya que existen ciertos patrones identificables que constituyen indicadores arqueológicos e iconográficos de matrimonios y otro tipo de pactos políticos establecidos por los Kanu'l con otros linajes y casas. Es por ello, que hay que señalar la importancia de los estudios iconográficos a nivel regional para definir patrones de representación ligados a ciertas unidades sociales y su distribución en el paisaje, con el fin de detectar influencias e interacciones en ciertos dominios.

En este trabajo, me centro en la descripción e interpretación de algunos rasgos formales y motivos icónicos que muestran distribuciones regionales significativas. Dichos patrones, en conjunto con los datos epigráficos y arqueológicos, nos permiten definir algunas de las estrategias sociopolíticas desarrolladas y empleadas por la dinastía Kanu'l durante el Clásico Tardío, con sede de poder en Calakmul². Así, me enfoco en la interacción entre los Kanu'l y sus aliados. Distintos tipos de afiliación fueron representados de diferentes maneras en el registro gráfico, el cual revela redes a nivel intersitio y sus efectos en el paisaje político. Este acercamiento interdisciplinario es un trabajo que deriva de mi investigación doctoral (Vázquez 2015), y da continuación a un estudio realizado junto con Ana García Barrios (García Barrios y Vázquez 2011, 2012) . $^{3}$.

\footnotetext{
2 En el Clásico Temprano, la sede de la dinastía Kanu'l fue Dzibanché. El establecimiento de una segunda sede en Calakmul probablemente se debe a una división del linaje Kanu'l a finales del siglo VI (ver Martin 2004, 2005; Velásquez 2004; Nalda 2004; Stuart 2012; Stuart et al. 2015a y b; Helmke y Awe 2016a, 2016b; Martin y Velásquez 2016).

3 Presenté una versión preliminar en el simposio «Las estrategias hegemónicas de la dinastía Kaan» organizado por Beniamino Volta, Kai Delvendahl y Nikolai Grube, en el Congreso Internacional de Mayistas, Izamal, Yucatán, junio de 2016.
} 


\section{Los programas visuales de los Kanu'l}

Este estudio parte de la hipótesis de que las imágenes relacionadas con la dinastía Kanu'l suelen representar cánones visuales altamente estandarizados. Existe un conjunto de elementos estandarizados y fácilmente identificables que caracteriza el discurso monumental estatal. Una vez que un patrón se identifica en un sitio específico, podemos sugerir un vínculo entre éste y los Kanu'l.

En las estelas relacionadas con los Kanu'l domina la representación del gobernante o de mujeres de alto rango, con atuendos elaborados y símbolos de poder y autoridad, asociados a actividades rituales y deportes políticos. A veces, el personaje principal está acompañado por cautivos humillados o enanos de la corte. Estos programas visuales ofrecen poca información sobre las relaciones sociales de los gobernantes con su propia unidad social o con otras. Así, la información directa contenida en la imagen misma es relativamente pobre debido a que los matrimonios y los pactos políticos entre dos o más unidades sociales o entidades políticas no son explícitos. Por esta razón, no me centraré aquí en el análisis de la imagen per se -para esto véanse los trabajos citados-, sino en la repetición de ciertos motivos y sus propiedades formales.

A grandes rasgos, los patrones que se identifican aquí como indicadores de las estrategias de cooperación e integración de las unidades sociales corresponden a tres códigos visuales distintos: 1) las estelas pareadas y escultura en bajo relieve que representan parejas mujer-hombre para expresar alianzas matrimoniales o la relación madre-hijo; 2) el atuendo ceremonial del traje de red que refleja la participación en un culto estatal; y 3 ) la práctica del juego de pelota que se aprecia en paneles de escalinatas jeroglíficas. Se verá en adelante, que no son los motivos en sí los que revelan la afiliación política de los autores de estos monumentos, sino que encontramos el significado político en la manera en que fueron realizados, es decir en los formatos y las convenciones de composición, así como en los contextos arquitectónicos y espaciales en los cuales se ubicaron. A continuación, presentaré un análisis más detallado de los programas visuales mencionados con el fin de determinar su relevancia en el sistema de estrategias sociopolíticas de los Kanu'l.

\subsection{Las estelas pareadas}

Las estelas pareadas fueron un tipo de medio visual común e importante ligado a la dinastía Kanu'l, y han sido objeto de diferentes estudios (Marcus 1987, 1992; Joyce 2000; Reese-Taylor et al. 2009; Stewart 2009; García Barrios y Vázquez 2011, 2012; Vázquez 2015; Jabłońska 2016). Estas estelas frecuentemente representan a la pareja real, aunque en algunos casos la mujer es la madre del gobernante, como se observa en ejemplos de Naranjo.

Existen tres formatos básicos de estelas pareadas. El más común corresponde a dos monolitos verticales (Cuadro 1a). En cada uno se representa a un personaje, de tal manera que las figuras se miran entre sí. En otras ocasiones, se trata de un solo monolito, con un personaje en el frente y otro en el reverso (Cuadro 1b). En formatos derivados, como tableros de dimensiones menores, se llegó a representar a la pareja real en una sola superficie (p. ej. Elemento 19, La Corona). El formato más recurrente y diagnóstico empleado por la dinastía Kanu'l es el de dos monolitos. Estos medios visuales frecuentemente se ubican en la entrada de un edificio, como las 


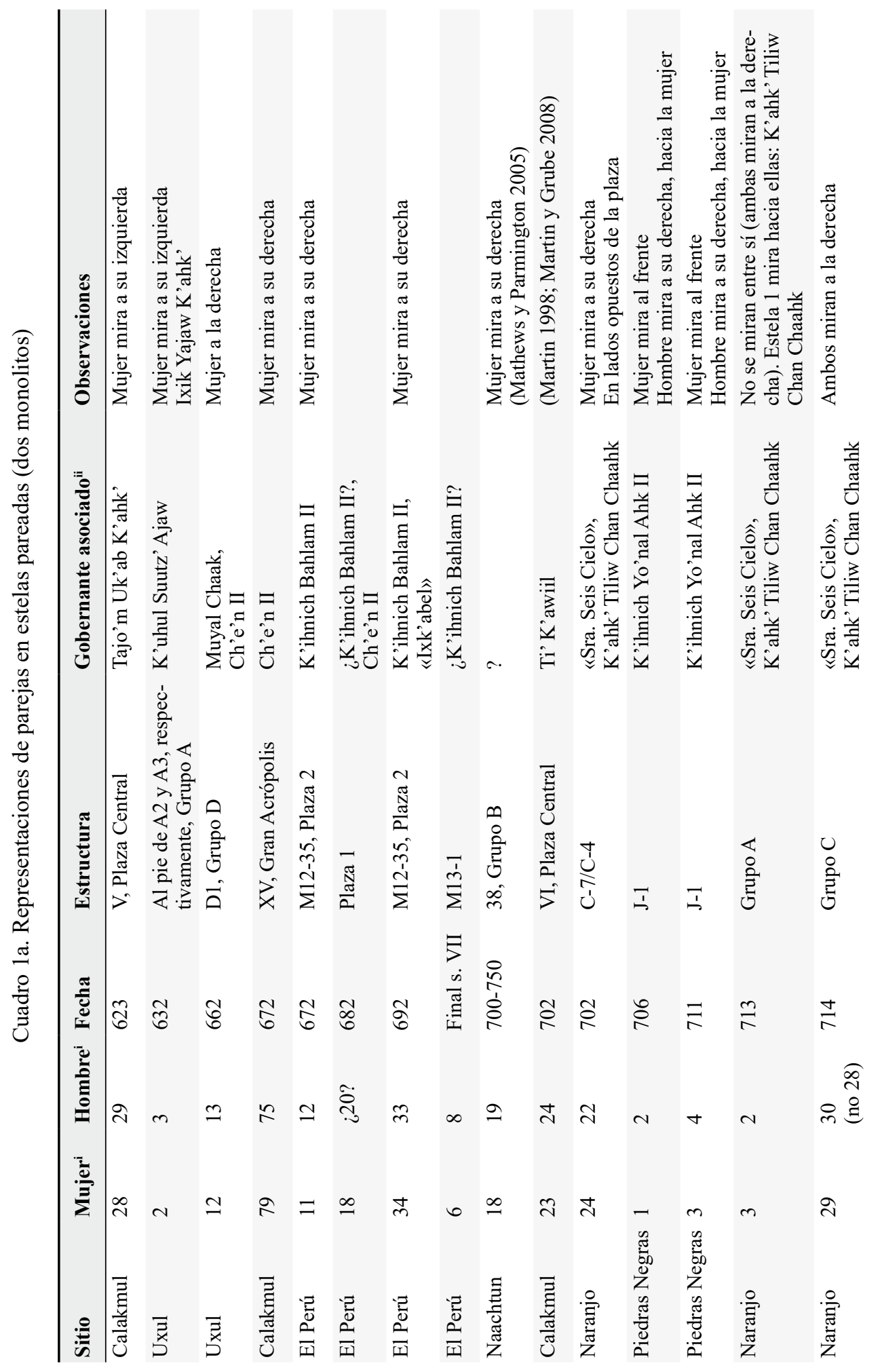




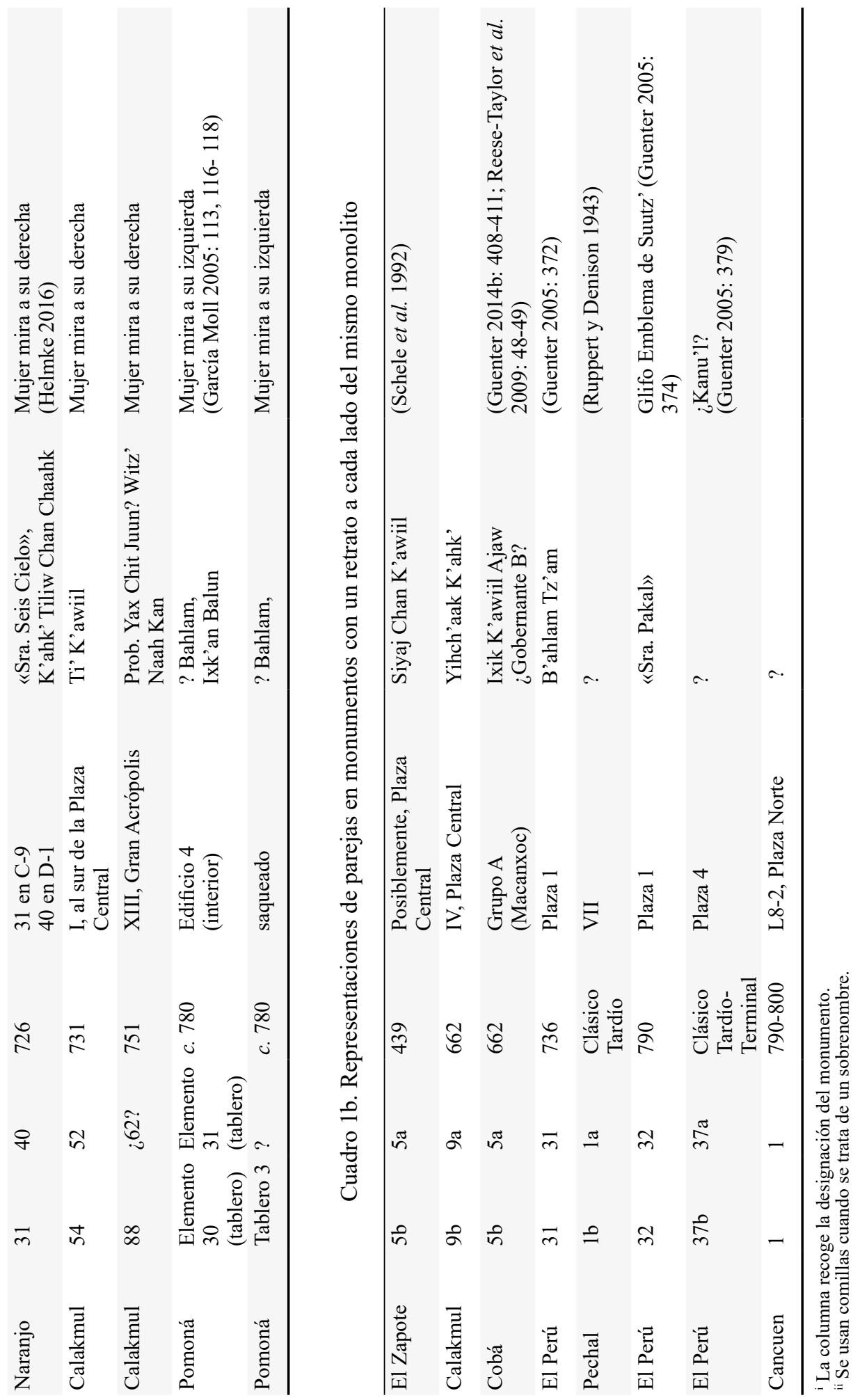




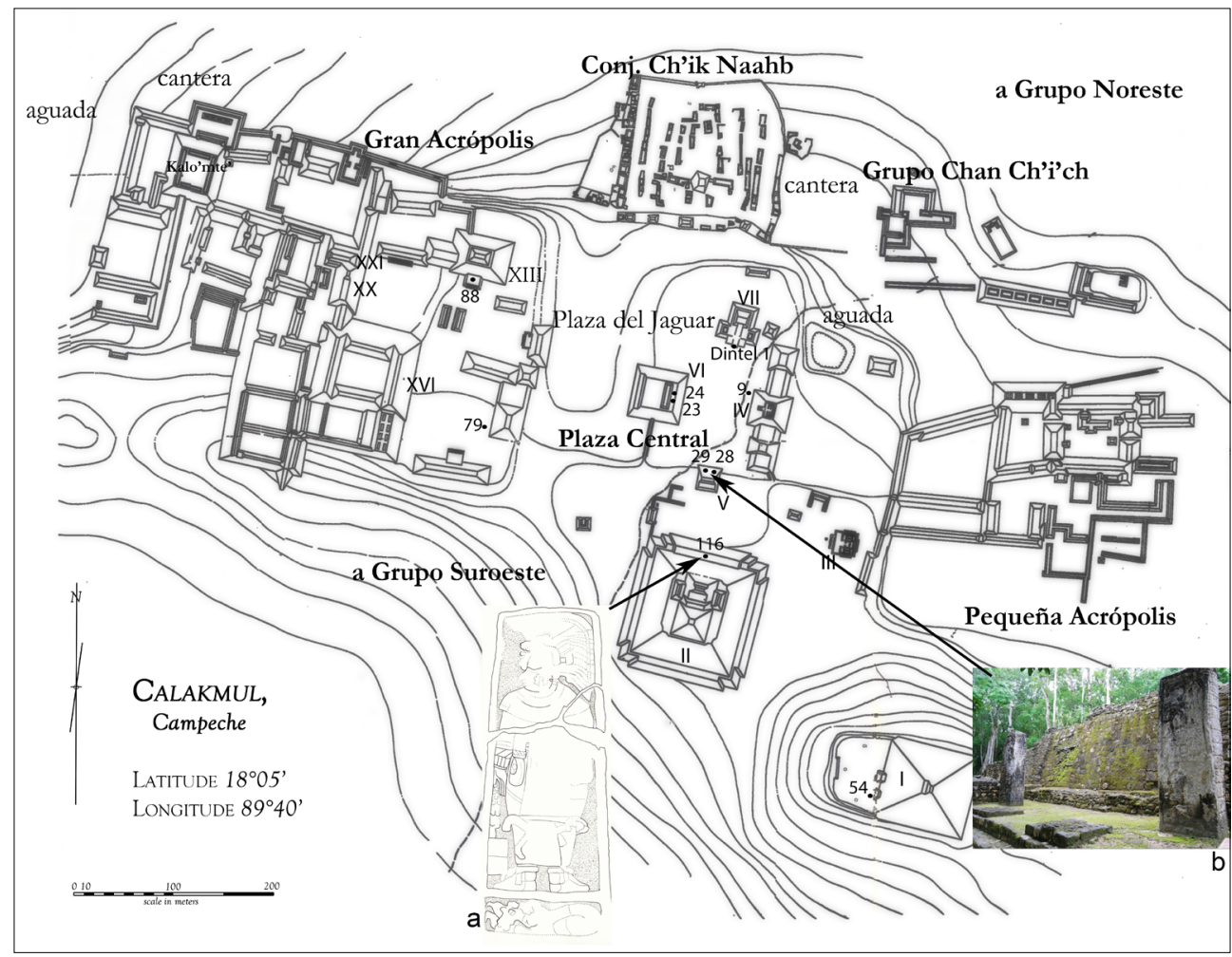

Figura 1. Área nuclear de Calakmul. Representaciones de mujeres en el discurso monumental (áreas públicas y semipúblicas): a) Estela 116 muestra a una mujer realizando un ritual de esparcimiento de incienso (dibujo de Rocío García Valgañón realizado en 2008).

b) Estelas pareadas 28 y 29, Estructura V (modificado de Rupert y Denison 1943).

estelas 23 y 24 en la Estructura VI o las 28 y 29 en la fachada norte de la Estructura V, ambas en la Plaza Central de Calakmul (Figura 1b), o las estelas 12 y 13 de Uxul que flanquean la escalinata central de la Estructura D1. Otra ubicación común de estas estelas es al pie del basamento, como la Estela 9 en la Estructura IV o las estelas 75 y 79 en la Estructura XV de Calakmul. La ubicación de las estelas pareadas en distintos sitios (Cuadros 1a y 1b, Figura 1) revela una preferencia por los espacios públicos y semipúblicos, siendo Calakmul la ciudad donde se ha registrado el mayor número de éstas (seis juegos).

La mayoría de estas estelas, además de representar a la pareja real, también comparten otros rasgos, como la mujer vistiendo un traje de red. Observamos una tendencia a representar individuos de menor rango social mirando hacia su izquierda, mientras que los de mayor rango ven a su derecha, reflejando un principio de direccionalidad común en el arte maya que está presente en diferentes tipos de medios ( $\mathrm{p}$. ej. cerámica, escultura, murales, etc.). El reportorio de convenciones iconográficas que codifican el estatus social ha sido estudiado por diferentes investigadores (p. ej. Miller 1981, 1983; Houston 1998; Houston y Stuart 2001; Marcus 2006; Velásquez 2009). Aquí propongo, con base en el contexto de las representaciones, que la recurrencia de mostrar a las mujeres a la izquierda o a la derecha del observador puede 
ser un indicador de hipergamia o hipogamia, respectivamente. En este canon iconográfico las posturas, gestos, títulos y atuendos son tan importantes como la posición relativa de cada personaje en el espacio de representación (Velásquez 2009: 266), ya que el espacio no es homogéneo sino relativo y jerárquico (Houston y Stuart 2001: 62). En la mayoría de las estelas pareadas de Calakmul, excepto por las estelas 88 y 54, las mujeres miran a su izquierda -hacia el gobernante Kanu'l, figura de mayor rango social. Muchos ejemplos fuera de Calakmul muestran lo opuesto, i.e. la mujer mira a la derecha, como en Naranjo, El Perú y La Corona, entre otros (Figura 2). La evidencia epigráfica sólida confirma que estas mujeres eran miembros de casas de mayor rango que las de sus esposos ${ }^{4}$. En la Estela 34 de El Perú, «Ixk'abel»-una ixkanu'l ajaw, hija de Ch'e'n y hermana de Yihch'aak K'ahk' - mira a su derecha, hacia la Estela 33, que representa a K'ihnich Bahlam, gobernante de El Perú y vasallo de los Kanu'l (Figura 2d). En las estelas 3, 24, 29 y 31 de Naranjo, la Señora Seis Cielo está viendo a su derecha (Figuras 2e y 2f). En el Elemento 19 de La Corona la mujer también mira a su derecha, donde se encuentra su esposo Chak Naahb Chan, gobernante de Saknikte' (La Corona) (Figura 2c). Así, la postura de la mujer en estos monumentos es un indicador de matrimonio hipogámico, donde la mujer pertenece a un grupo de parentesco de mayor estatus social que el de su esposo. En este tipo de matrimonio virilocal, la mujer deja su residencia natal para mudarse a la de su cónyuge, de menor rango. Estos matrimonios se establecían con el fin de vincular capitales regionales con centros secundarios, aumentando el estatus de los últimos (Marcus 1992: 259).

Las estelas 28 y 29 de Calakmul, posiblemente dedicadas en 623, muestran a la pareja real y son el ejemplo más temprano de estelas pareadas en Calakmul y en el área maya (Reese-Taylor et al. 2009: 63). Las estelas 75 y 79 de Calakmul -al pie de la Estructura XV en la Gran Acrópolis- se asocian con Ch'e'n II ${ }^{5}$ (636-686) (Ruppert y Denison 1943; Martin 1998), mientras que las estelas 52 y 54, originalmente ubicadas en la Estructura I y asociadas con Ti' K'awiil (702-733), son dos de los ejemplos más tardíos de Calakmul. El ejemplo más tardío de este sitio es el par de las estelas 88 (Figura 2b) y 62 (751) en la Estructura XIII de la Gran Acrópolis, relacionadas con el gobernante Yax Chit Juun? Witz' Naah Kan. Además de Calakmul, El Perú, Naranjo y Uxul, también se han encontrado estelas pareadas en Cancuen, Cobá, Naachtun y Piedras Negras, entre otros sitios (Cuadros 1a y 1b, Figura 3). De acuerdo con los Cuadros 1a y b, la producción de estas estelas se inició en 623 en Calak-

\footnotetext{
${ }^{4}$ Los matrimonios hipogámicos están bien atestiguados epigráficamente en La Corona (p. ej. Panel 6), pues tenemos referencias glíficas explícitas, pero en otros casos los indicadores están más codificados ya que no hay expresiones de parentesco en los textos, p. ej. en los monumentos de El Perú. Otros ejemplos de este tipo de patrón matrimonial es el caso de la Señora Seis Cielo, una ixmutu'l ajaw de Dos Pilas, enviada a Naranjo en 682 a reinstaurar la autoridad política mediante su matrimonio con el gobernante local y dando luz al futuro gobernante de Naranjo (Martin y Grube 2008: 74-77). De hecho, ella fue la autoridad política por un largo periodo antes de que su hijo accediera al trono (Helmke 2016). El caso de Naranjo no involucra una ixkanu'l ajaw, pero la Señora Seis Cielo fue un miembro de la dinastía Mutu'l de la rama de Dos Pilas, leal y cercano aliado de los Kanu'l, por lo que se infiere una fuerte influencia de este último. En términos de alianzas matrimoniales como estrategias sociopolíticas, se puede sugerir que los Kanu'l debieron haber fungido como intermediarios en el matrimonio de la Señora Seis Cielo y su esposo con el fin de estabilizar las tensiones políticas en el área de Naranjo.

5 También conocido como Yuhkno'm Ch'e'n o Yuhkno'm Ch'e'n El Grande (Martin y Grube 2008: 108), en adelante lo referiré como Ch'e'n. Yuhkno'm Ch'e'n I gobernó en Dzibanche, mientras Ch'e’n II llevó a su época de esplendor a la dinastía Kanu'l con sede en Calakmul. Es posible que yuhkno' $m$ sea un título que portaron varios gobernantes de la dinastía Kanu'l, aunque no de manera exclusiva, así que opto por no usar esta expresión cuando se refiera a los gobernantes Kanu'l.
} 


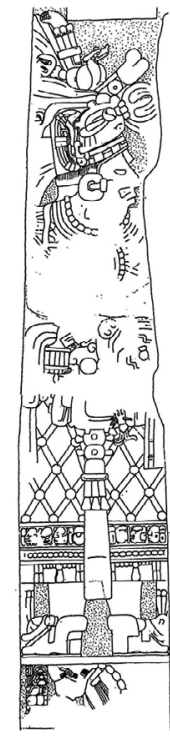

a

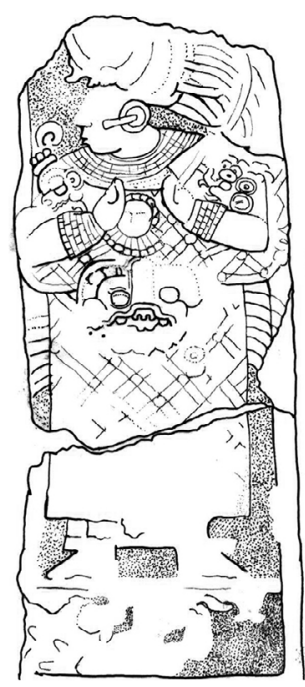

b

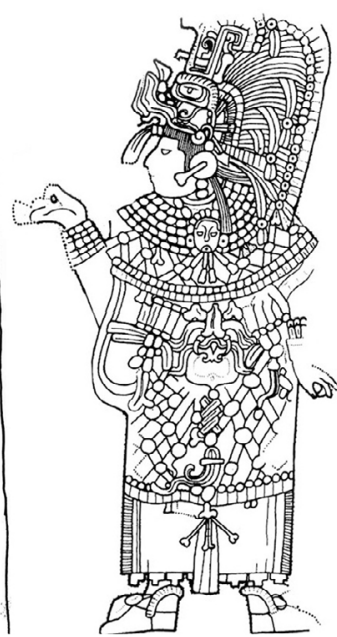

C

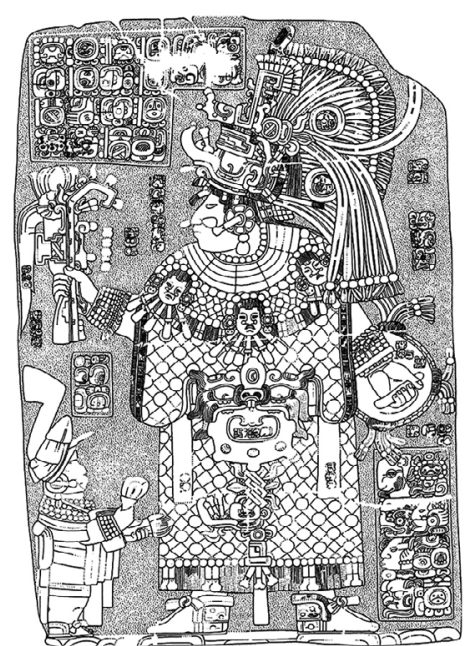

d

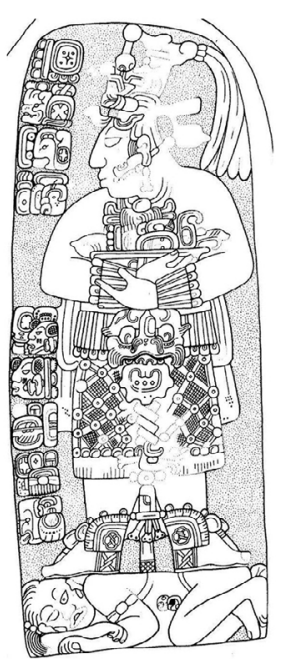

e

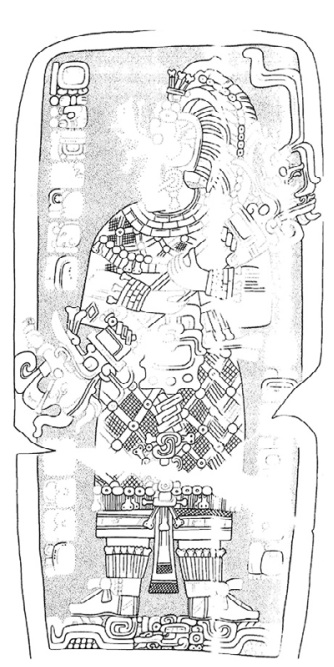

f

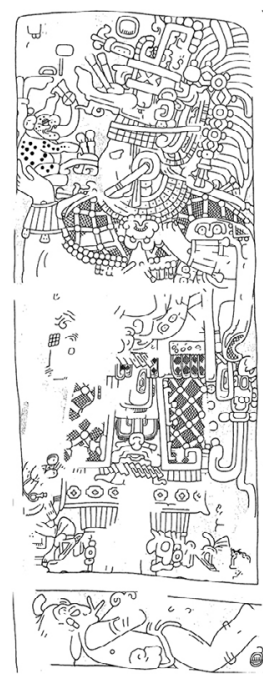

g

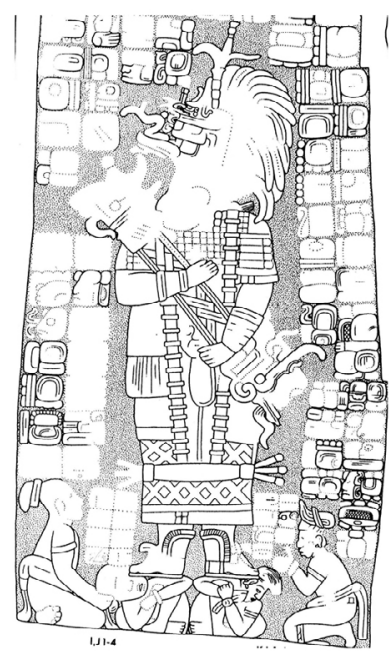

$\mathrm{h}$

Figura 2. Mujeres en traje de red: a) Calakmul, Estela 9 (dibujo de Eric von Euw); b) Calakmul, Estela 88 (dibujo de Asier Rodríguez Manjavacas realizado en 2008); c) La Corona, Elemento 19 (dibujo de Nikolai Grube en Martin y Stuart 2009); d) El Perú, Estela 34 (Montgomery 2000); e) Naranjo, Estela 24 (Graham y von Euw 1975); f) Naranjo; Estela 31 (Graham 1978); g) Xultun, Estela 24 (von Euw y Graham 1984); h) Cobá, Estela 1 (Graham y von Euw 1997). Todas las mujeres en estos monumentos miran a su derecha, excepto en la Estela 9 de Calakmul. 


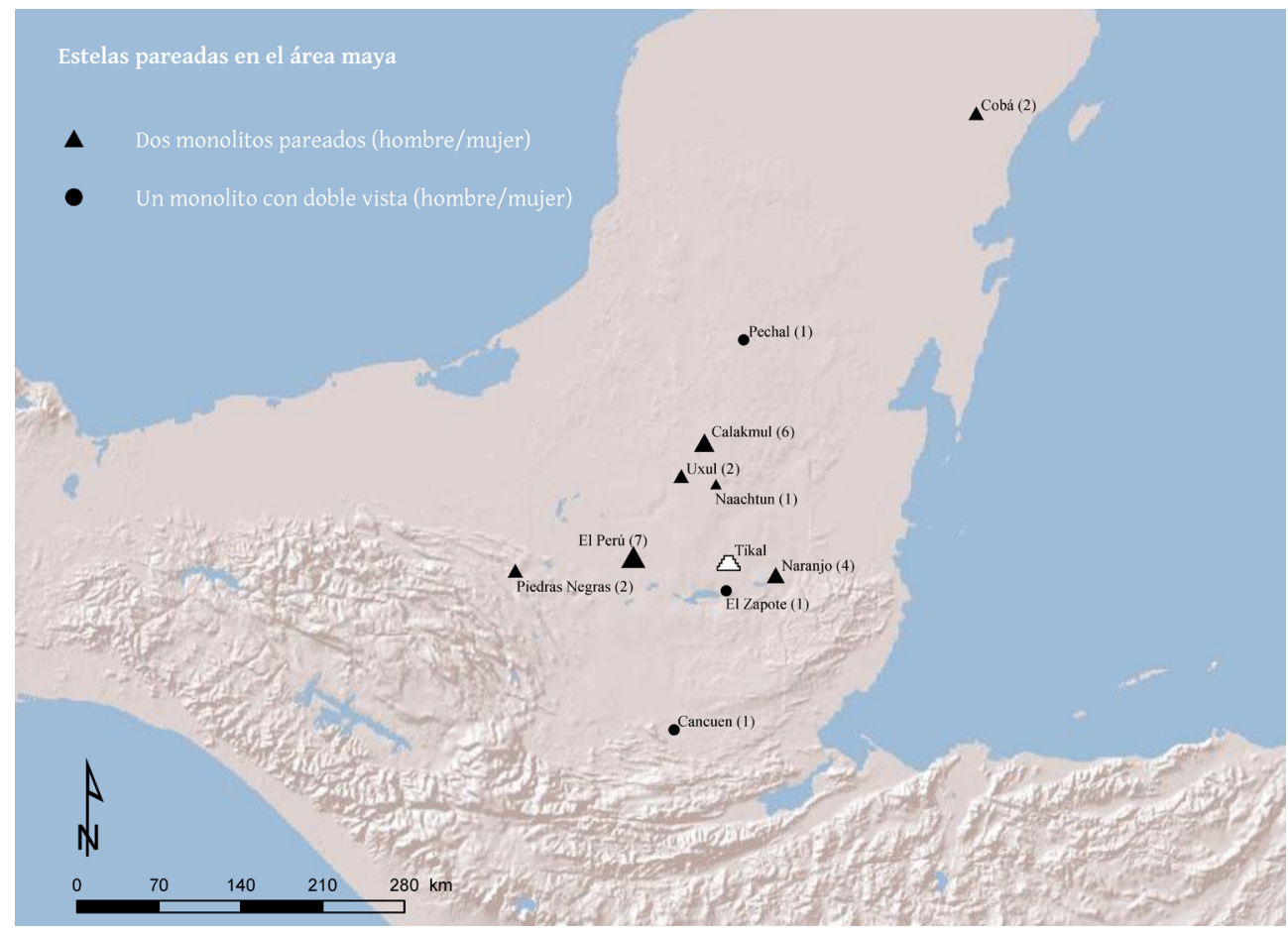

Figura 3. Distribución de las estelas pareadas

(mapa realizado por Felix Kupprat y Verónica A. Vázquez López).

mul y se dispersó ampliamente durante los gobiernos de Ch'e'n, Yihch'aak K'ahk' y Ti' K'awiil (entre 623 y 736).

Cabe aclarar que los pares de estelas tienen antecedentes fuera de Calakmul en el Clásico Temprano. Un ejemplo del siglo V son las estelas 1 y 2 de Tikal (Jones y Satterthwaite 1982: 9-11) que, al parecer, fueron erigidas juntas, portando dos retratos del gobernante, uno enfrentando al otro, en distintos atuendos ceremoniales. No obstante, en los casos tempranos no se han identificado mujeres, las cuales son tan importantes y distintivas de las estelas pareadas del Clásico Tardío. De la misma manera, la Estela 5 de El Zapote es un antecedente importante pero aislado para el formato de hombre y mujer en dos lados opuestos. Aparentemente, los escultores del siglo VII recurrieron a prototipos antiguos para la creación del canon de estelas pareadas en Calakmul.

Otro aspecto interesante es que los ejemplos más tempranos de este nuevo canon de representar a la pareja real tampoco se asocian claramente con la dinastía Kanu'l. Las estelas 28 y 29 de Calakmul están muy erosionadas por lo que no se puede leer el nombre del gobernante ni el glifo emblema. Simon Martin (1998) ha reconstruido cuatro fechas entre 620 y 623 en la Estela 29. Debido a la mención de 623, se ha asumido que estos monumentos fueron erigidos por Tajo'm Uk'ab K'ahk', conocido por la Estela 22 de Caracol y la llamada escalinata jeroglífica de Naranjo; pero no existen textos que confirmen su residencia en Calakmul. Con base en la nueva evidencia epigráfica (ver Stuart 2012; Helmke y Awe 2016a, 2016b; Martin y Velásquez 2016), en 623 la sede de poder de la dinastía Kanu'l parece haber sido Dzibanche, 
pues la «reinstauración» del poder político en Calakmul al parecer ocurrió al menos una década más tarde, en 635 (Stuart 2012). El segundo ejemplo más temprano de estelas pareadas corresponde a las estelas 2 y 3 de Uxul (632). La Estela 2 representa a una mujer que porta los títulos $k$ 'uhul chatahn winik y sak wahyis, mientras que la Estela 3 muestra un k'uhul suutz' ajaw y kalo'mte' (Grube 2008: 217-220). Estos dos personajes parecen haber pertenecido a linajes importantes, lo cual nos deja dos posibles interpretaciones: 1) el canon visual fuertemente ligado con la dinastía Kanu'l después de 635 fue originalmente creado por otras unidades sociales, anterior a la «llegada» de los Kanu'l a Calakmul, o 2) los Kanu'l ya tenían una influencia considerable en Calakmul y los alrededores antes de 623. La segunda opción es tentadora, considerando cierta evidencia para una alianza cercana entre los Kanu'l y los Chatahn en el siglo VII, que bien podría remontarse a finales del siglo VI (Vázquez et al. 2016).

Por ende, reafirmo que la aparición y proliferación de dos monolitos formando estelas pareadas está estrechamente ligada al desarrollo de la hegemonía Kanu'l, claramente concentrado en las Tierras Bajas Centrales, rodeando el área de Tikal, pero excluyéndola (Figuras 3 y 6a), con un rango temporal entre 623 y 736 (17 / 18 apariciones, ver Cuadro 1a). La variante formal que representa a la pareja en un solo monolito está más dispersa en espacio y tiempo (Figura 3 y Cuadro 1b). Su área focal está menos definida y muchas apariciones son posteriores a 736 (i.e. 3 o 4 de 8 , ver Cuadro 1b).

Las estelas pareadas son evidencia clara de la importancia de la mujer en la arena política, cuyas representaciones frecuentemente fueron parte del discurso público, como lo refleja el contexto espacial (ver Figura 1). Estos monumentos también proyectan la relevancia de las relaciones por afinidad y afiliación como factores fundamentales en las estrategias de reproducción política, donde las relaciones matrimoniales y la herencia materna fueron componentes importantes (Vázquez 2011, 2014, 2015).

La mujer -como transmisora de poder y procreadora de gobernantes- tuvo un papel fundamental en la reproducción de su unidad social y en el establecimiento de las redes políticas entre diferentes casas (García Barrios y Vázquez 2011: 85; Vázquez 2014: 140-141). Su importancia no se limitaba a su capacidad de procrear gobernantes, sino también como legitimadora de su esposo en el trono, particularmente en casos que siguen patrones hipogámicos.

\subsection{Las mujeres y el traje de red}

El segundo patrón iconográfico difundido por los Kanu'l corresponde a mujeres vistiendo el traje de red. Los orígenes, el desarrollo formal y el significado simbólico de esta vestimenta ha sido discutido en trabajos anteriores (Reese-Taylor et al. 2009; García Barrios y Vázquez 2011, 2012). El traje de red se define a través de un patrón de cuentas redondas y alargadas que definen un patrón de líneas cruzadas que se asemejan al tejido de una red. En ejemplos tempranos, el traje se compone únicamente de una falda, o bien, por dos piezas, añadiendo un keechkemitl ${ }^{6}$ o capa corta (García Barrios y Vázquez 2011, 2012). El tocado asociado presenta la cabeza de una serpiente estilizada con un símbolo triádico y un ornamento de plumas (Proskouriakoff

\footnotetext{
También aparece como quexquémitl o quechquémitl del náhuatl quechquemitl.
} 
1961; Taube 1992; Le Fort 2002: 33). Las representaciones del Clásico Temprano contienen rasgos que se volvieron dominantes en el traje del Clásico Tardío (Proskouriakoff 1961: 98), cuando, además, se nota el desarrollo del huipil largo como variante distintiva (García Barrios y Vázquez 2011, 2012).

El traje de red asociado con las mujeres tiene características específicas como el cinturón de la cabeza de xook y la concha Spondylus (ver Figura 2). Las mujeres representadas con este atavío tienden a portar un tocado que ostenta una cabeza de serpiente con nariz alargada. En algunos ejemplos, el tocado lleva una serpiente de agua esquemática (ver Gómez en prensa), y la mujer presenta un peinado escalonado (estelas 9 de Calakmul y 34 de El Perú; García Barrios y Vázquez 2011: 70; también ver Proskouriakoff 1961 para elementos asociados al traje de red). Rasgos comunes en estas composiciones son la presencia de cautivos sobre los que se yergue la mujer (estelas 9 [ver Figura 2a], 28 y 88 [ver Figura 2b] de Calakmul, 24 de Naranjo [ver Figura 2e], 1 [ver Figura 2h] y 4 de Cobá, 24 [ver Figura 2g] y 25 de Xultun), atributos bélicos como escudos (Estela 34 de El Perú [ver Figura 2d]) e insignias rituales (Estelas 34 de El Perú, 24 de Naranjo [ver Figura 2e]) (Proskouriakoff 1961: 96-98). Pocas de estas representaciones incluyen a un enano, p. ej., Estela 34 de El Perú, y estelas 24 y 25 de Xultun. El elemento más constante en estas imágenes es el cinturón con la cabeza de xook y la concha, que se vuelve un indicador diagnóstico.

El traje de red se ha asociado con el dios del maíz que renace en el otro mundo acuático (Quenon y Le Fort 1997; Le Fort 2002; García Barrios y Vázquez 2011, 2012) o con la diosa de la luna (Schele et al. 1992; Reese-Taylor et al. 2009). El tocado de serpiente con un plato de ofrenda que frecuentemente aparece con él, además es típico del dios G1 en su forma temprana (Hellmuth 1987; ver Gómez en prensa), por lo cual parece que la red en sí es un atributo de deidades acuáticas. Este atuendo lo visten mujeres realizando actividades rituales como, p. ej., el esparcimiento de incienso (uchokow ch'aaj), de los que encontramos dos ejemplos en Calakmul, en el Dintel 1 de la Estructura VII y en la Estela 116 de la Estructura II (ver Figura 1a). El traje de red tiene también connotaciones bélicas y expresa el poder político (ReeseTaylor et al. 2009; García Barrios y Vázquez 2011, 2012). Una propuesta reciente mantiene que el traje de red también está relacionado con el culto a la serpiente acuática Yax Chit Juun Witz' Naah Kan, deidad patrona de los Kanu'l en Calakmul, que fue personificada por varias mujeres que lo vestían (Vázquez y Kupprat 2018: 90-92). De esta manera, hay que considerar que la vestimenta también era un instrumento dentro de prácticas rituales específicas, posiblemente como parte de la ritualidad estatal. En los párrafos siguientes, me centro en las representaciones de la mujer vistiendo el traje de red, por su aparente conexión con la dinastía Kanu' $1^{7}$.

La evidencia muestra que no sólo las ixkanu'l ajaw fueron representadas con el traje de red, sino también aquellas relacionadas con otras unidades sociales aliadas a la dinastía Kanu'l (Cuadro 2, Figura 4a), por lo que se ha sugerido que la parafernalia del traje de red indica algún tipo de afiliación con esta dinastía, constituyendo un símbolo de poder y legitimación (García Barrios y Vázquez 2011, 2012; ver también Reese-Taylor et al. 2009). No obstante, los patrones de distribución espacial y

\footnotetext{
En 2008, con Ana García Barrios comenzamos el estudio de la vestimenta de las mujeres Kanu'l y aquellas vinculadas a la dinastía; mismo que presentamos en la 13 ${ }^{\mathrm{a}}$ Conferencia Europea de Mayistas (EMC) en Paris, 2008. Continué con esta investigación en los años subsecuentes enfocada a las estrategias sociopolíticas. Parte de mi acercamiento al traje de red se basa en estos antecedentes.
} 


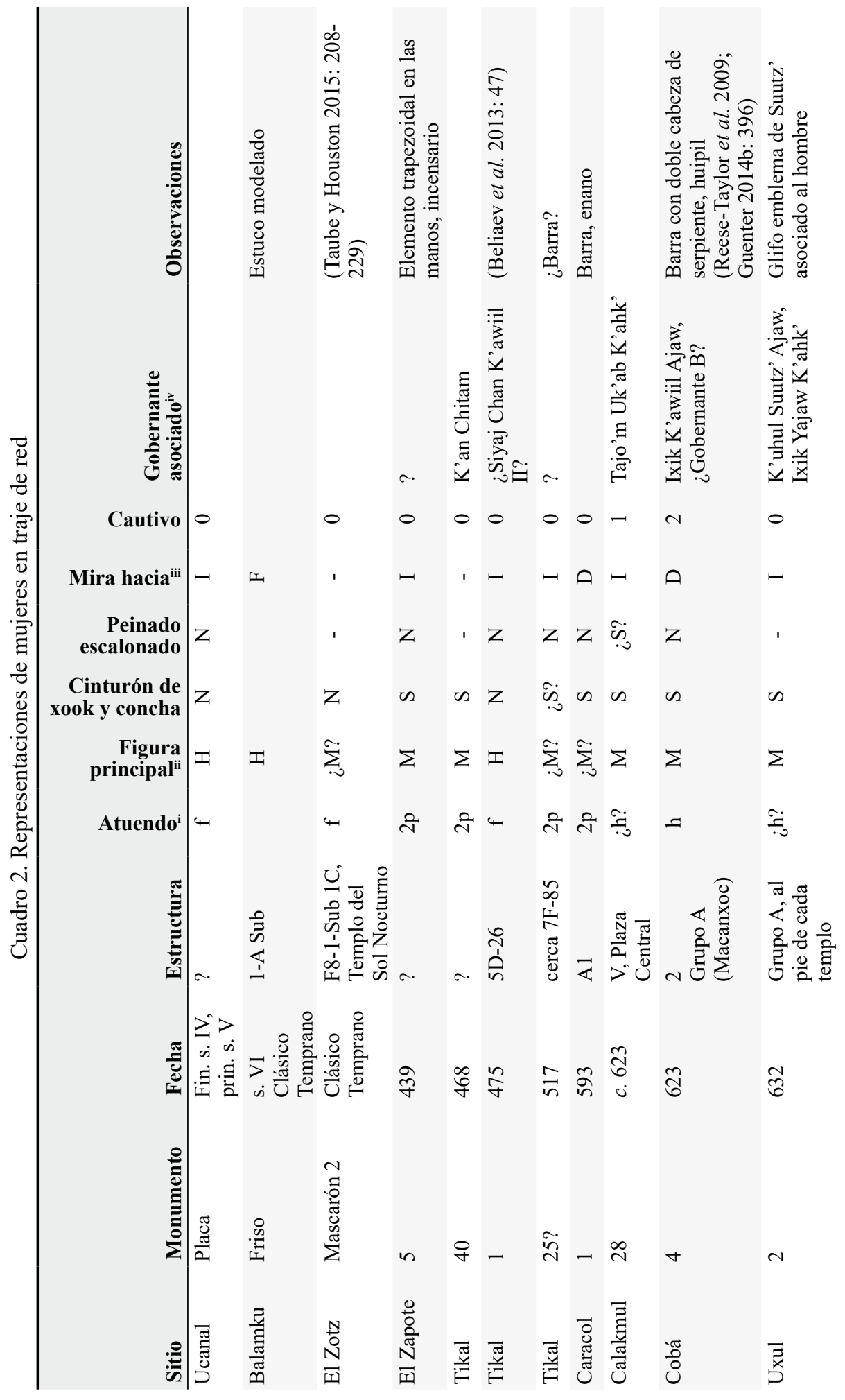



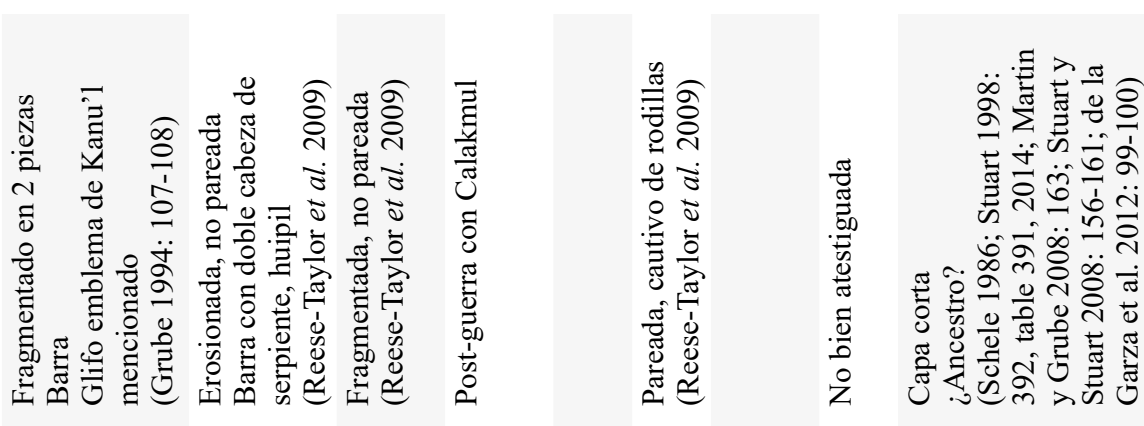

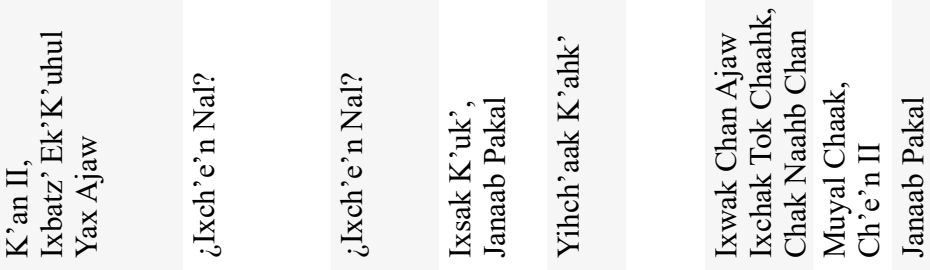
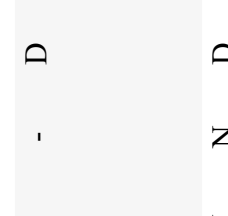

$\pm \Sigma \Sigma \Sigma \Sigma \Sigma \Sigma \Sigma \sum \sum_{i j}^{\infty}$

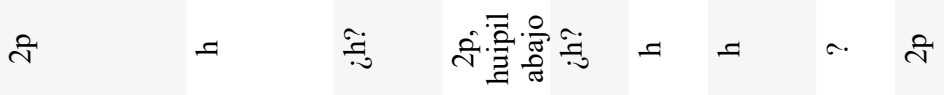

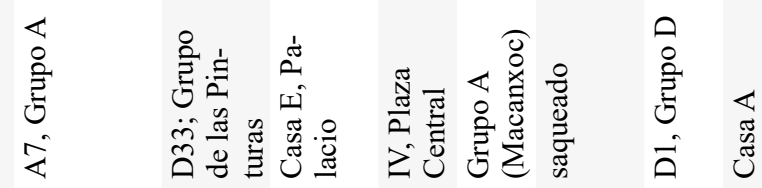

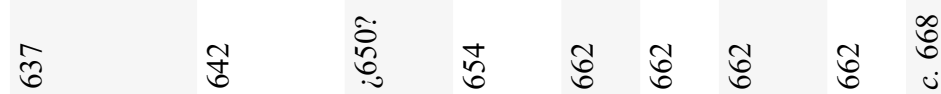

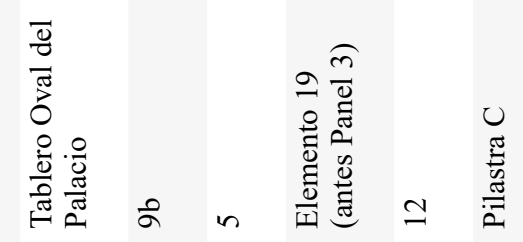

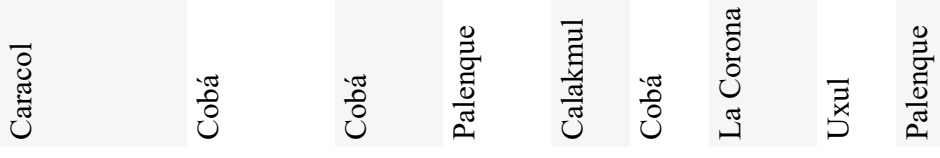

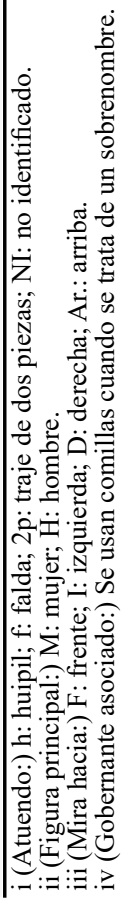




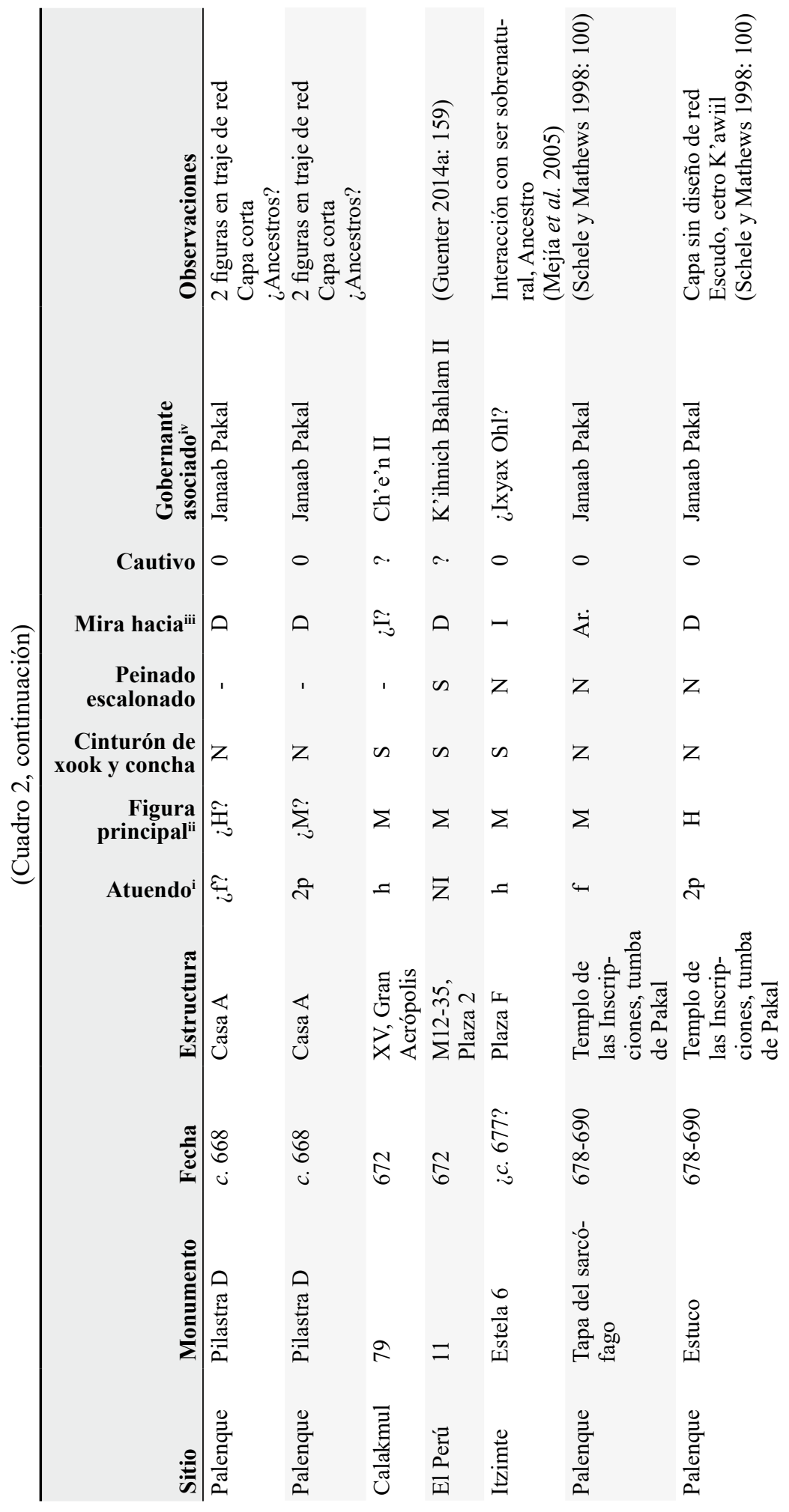



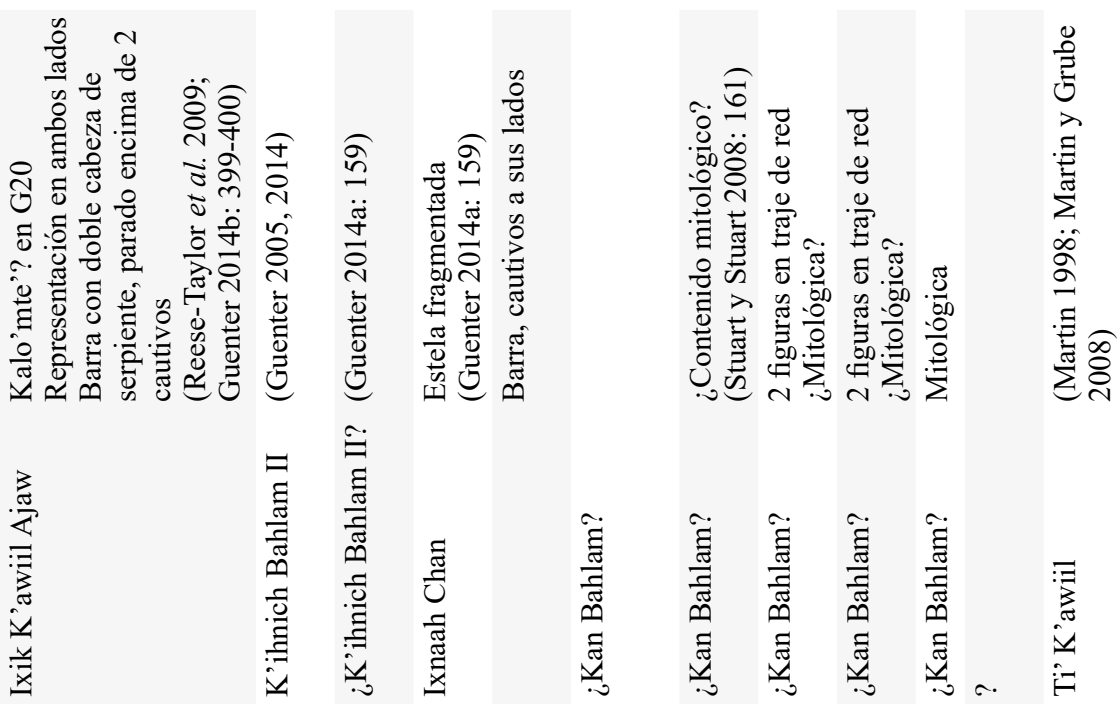

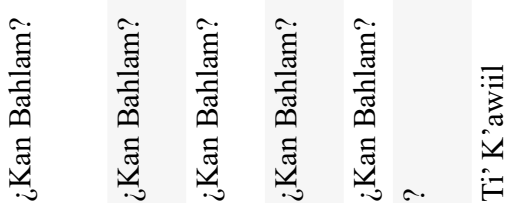
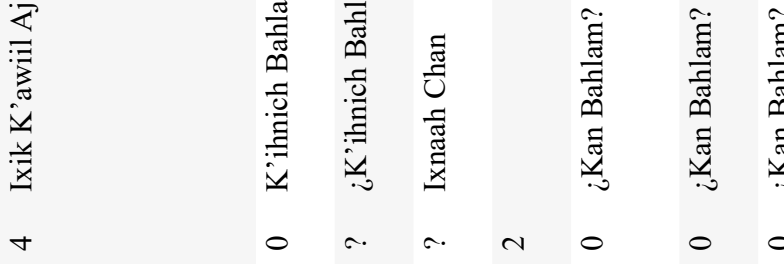

$$
\sum_{i=1}^{E}
$$
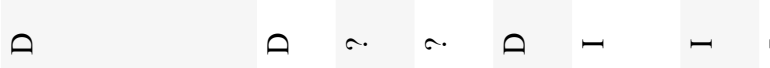

z

$$
z
$$

$$
\Sigma
$$$$
\Sigma \Sigma \Sigma I \Sigma \pm \Sigma \sum_{i=\Sigma \Sigma} \pm \Sigma
$$

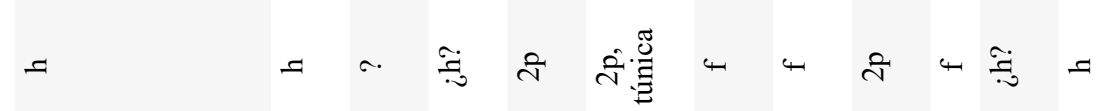

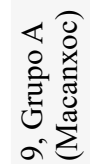

$\approx$

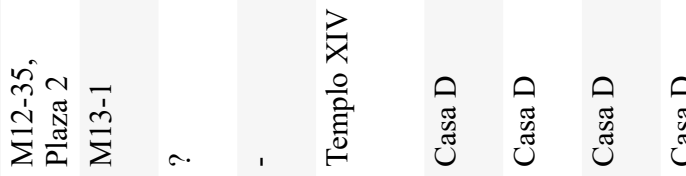

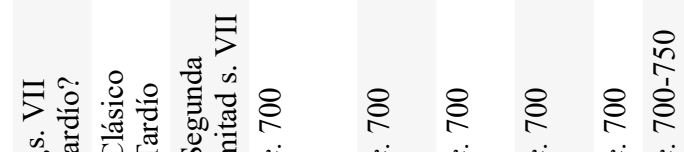

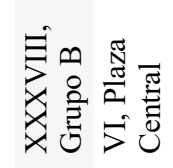

旁

乏

$\vec{x}$

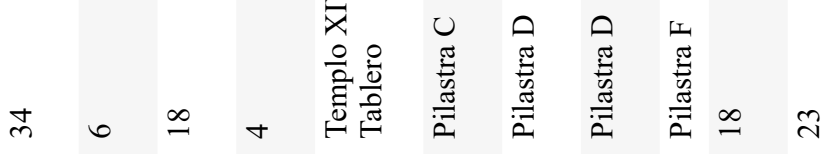

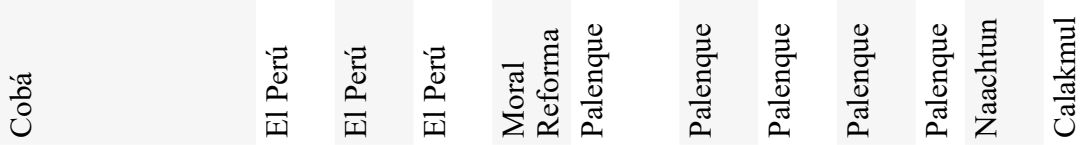

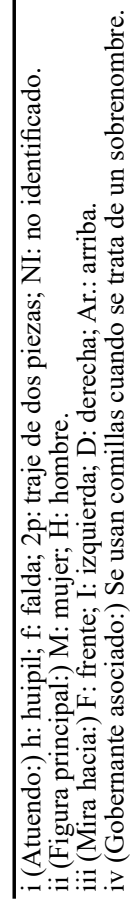




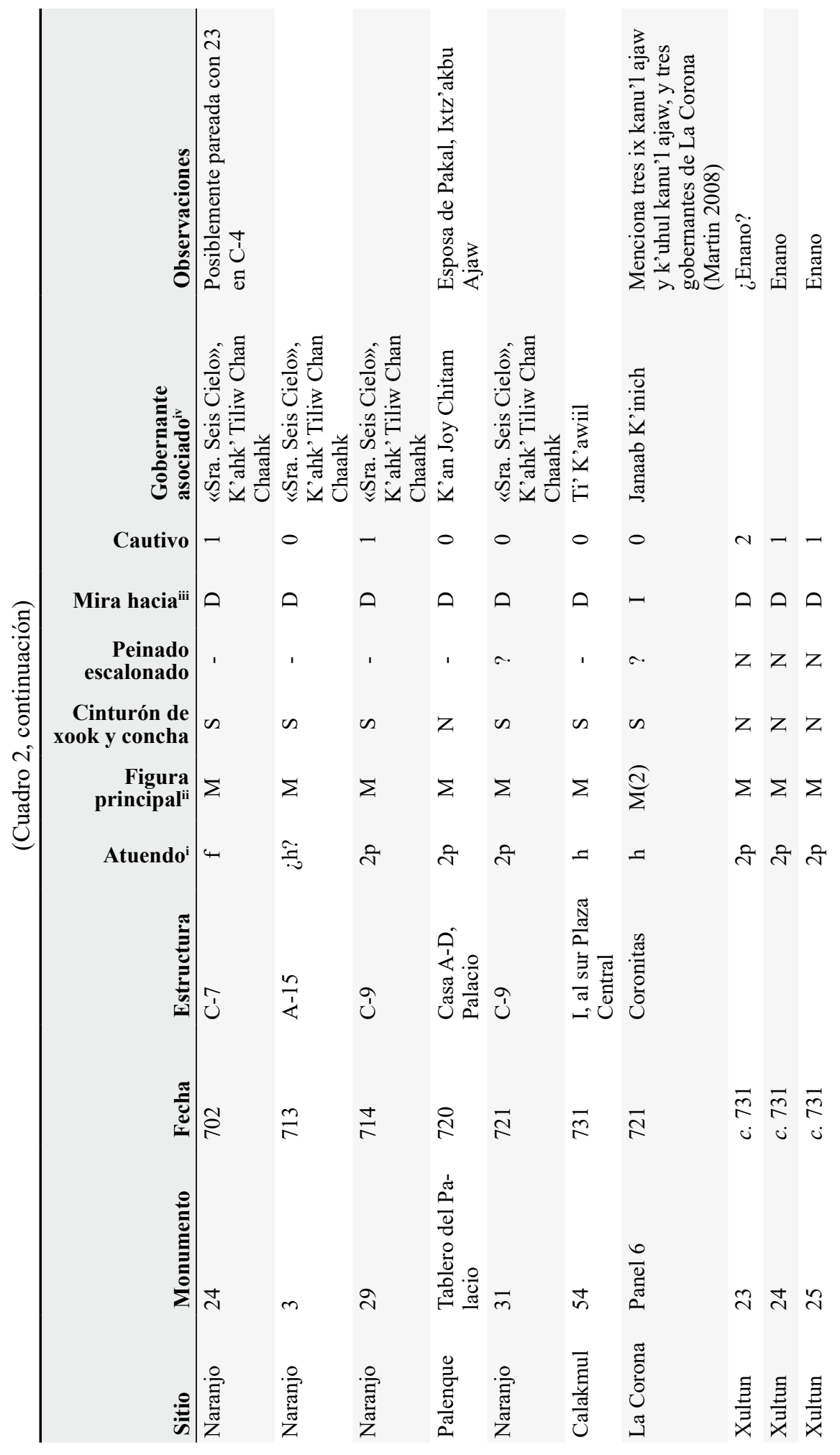


Vázquez López, V. A. Rev. Esp. Antropol. Amer. 49, 2019: 239-271

255

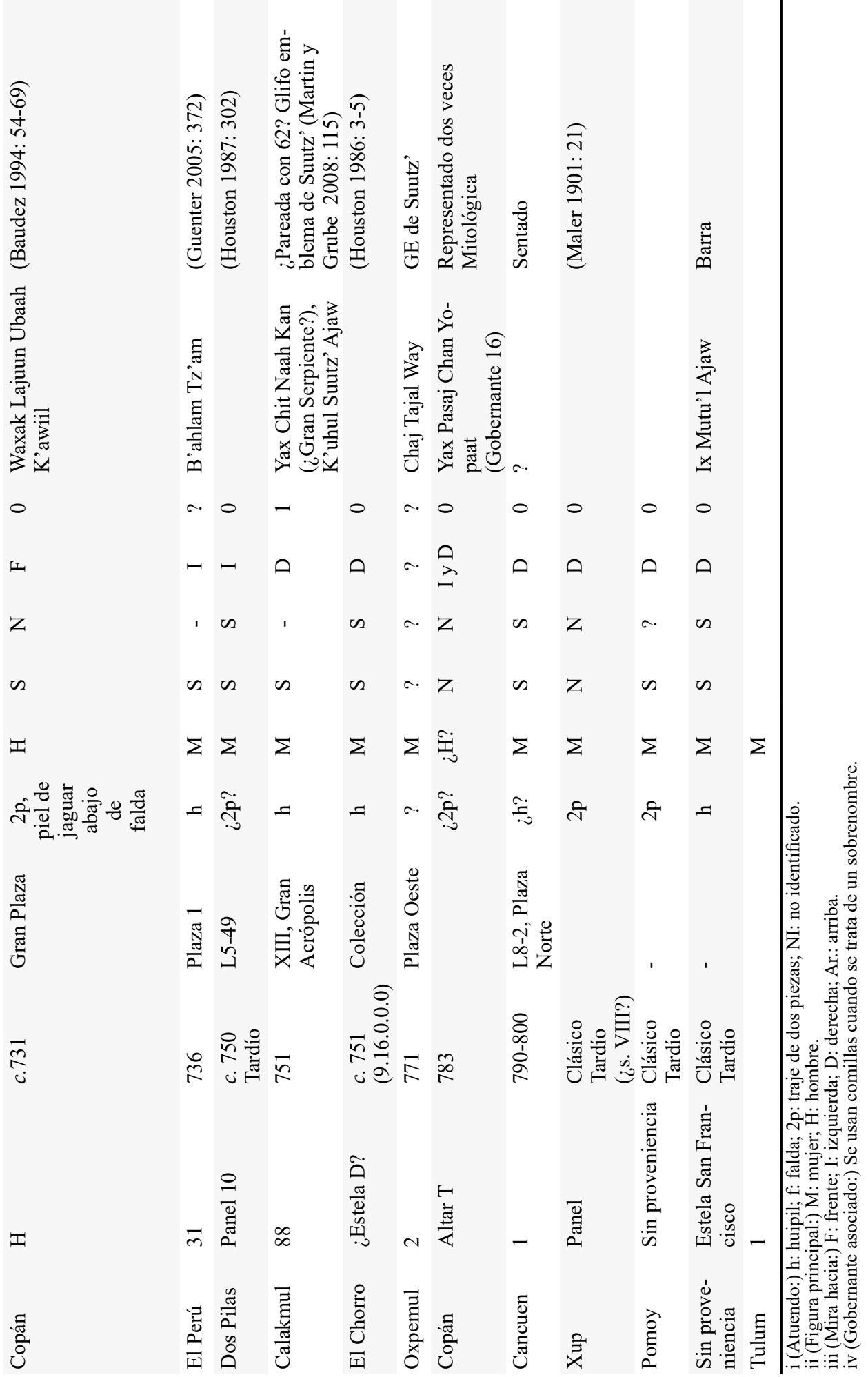



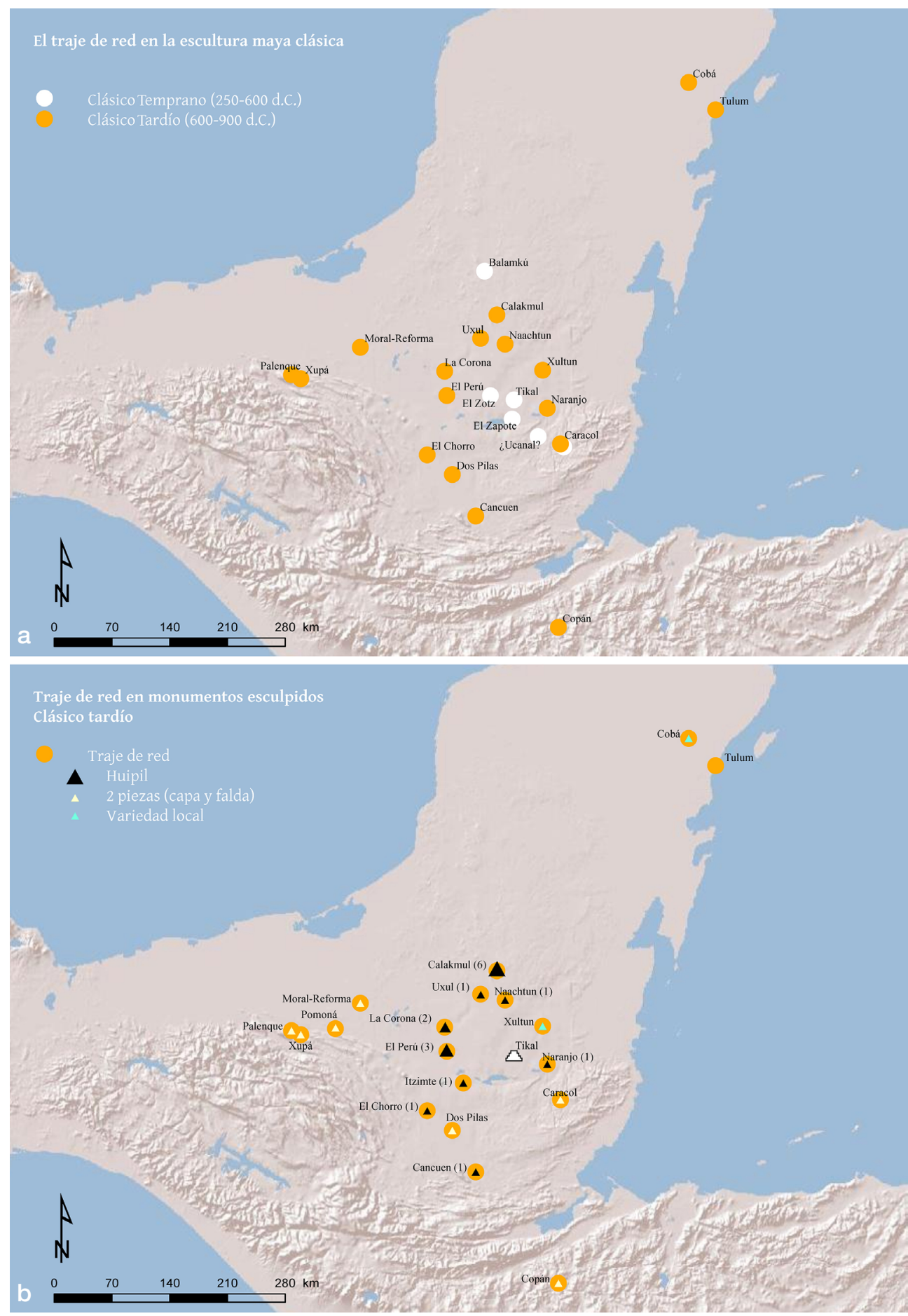

Figura 4. Distribución del traje de red: a) Clásico Temprano y Tardío; b) sus variantes estilísticas (huipil o túnica, traje de dos piezas [capa y falda] y variantes locales) (mapas realizados por Felix Kupprat y Verónica A. Vázquez López). 
temporal son menos claros que los de las estelas pareadas, por lo que se requiere una discusión detallada.

En primer lugar, se debe señalar que el traje de red no fue un invento de los Kanu'l, pues existen varios ejemplos del Clásico Temprano en que mujeres y hombres visten este atuendo (Cuadro 2, Figura 4a). Estos ejemplos datan de décadas, incluso siglos, antes de la estandarización del traje de red Kanu'1, y en algunos casos las representaciones no incluyen el cinturón con la cabeza de xook y la concha Spondylus (p. ej. el friso de Balamku y la Placa de Ucanal), que se volvería canónico en el Clásico Tardío (Figura 4a).

El segundo problema para detectar patrones de distribución es la existencia de estilos diferentes del traje de red (Figura 4b). Por ejemplo, en las estelas 1 (Figura 2h) y 4 de Cobá, y en la 24 (Figura 2g) y 25 de Xultun, el traje de red es diferente a los de Calakmul, La Corona y Naranjo (Figuras 2a-f). En Cobá, el traje es un huipil muy largo con una falda o corte ${ }^{8}$ por debajo y sin el cinturón de $x o o k$, mientras en la Estela 4 aparece un cinturón con tres máscaras de ancestros. El traje de red en Xultun tampoco incluye el cinturón de xook y la concha, y parece ser empleado por los hombres en una danza específica, como lo indica el texto de la Estela 25. Ambas variantes parecen representar desarrollos locales, que pudieron (o no) tener influencia de los procesos más amplios que discutiré más adelante.

Lo anterior nos lleva al tercer problema. El traje de red tampoco fue exclusivo de las mujeres del Clásico Tardío, ya que algunos hombres también lo vistieron en varias ocasiones, p. ej. Janaab Pakal en la lápida de su sarcófago o Waxaklajun Ubaah K'awiil de Copán en la Estela H (Cuadro 2). Sin embargo, los hombres a menudo (aunque no exclusivamente) vistieron la falda corta en lugar de la falda larga o el huipil. Los hombres que visten la falda de red suelen representar al dios del maíz (Quenon y Le Fort 1997; Le Fort 2002; García Barrios y Vázquez 2011, 2012), pero en los casos de las mujeres la identificación de una deidad asociada es más ambigua. Como hemos mencionado, el traje o falda de red se ha vinculado también con la diosa de la luna (Schele et al. 1992; Schele y Mathews 1998; Looper 2002; Reese-Taylor et al. 2009), con el dios G1 (Hellmuth 1987) e incluso con la serpiente acuática Yax Chit Juun Witz' Naah Kan, deidad patrona de los Kanu'l en Calakmul, esta última siendo el candidato más fuerte para el numen personificado por las mujeres en el Clásico Tardío (Vázquez y Kupprat 2018: 90-92). Esto indica que la vestimenta cumplía funciones rituales específicas, posiblemente como parte de un culto estatal. En este sentido, la vestimenta reflejaba también una identidad sociopolítica, estrechamente vinculada con los dioses patronos de la dinastía.

Un primer punto importante es que el traje de red aparece constantemente asociado con las esposas o madres de gobernantes vinculados con la esfera política Kanu'l en sitios como El Perú, La Corona, Naranjo y Uxul, entre otros (Cuadro 2). Algunos elementos que lo conforman han sido identificados en tumbas de mujeres. La Tumba 1 de la Estructura XV de Calakmul parece haber albergado a la esposa de Ch'e'n, madre de Yihch'aak K'ahk', la cual fue ataviada con un keechkemitl elaborado con cuentas de concha Spondylus y a la altura de la pelvis tenía una valva de la misma concha, lo que recuerda el importante elemento del cinturón (Carrasco et al. 1996, 1997; García Moreno 2001).

\footnotetext{
Corte o enredo es una falda larga y pesada que se dobla y enrolla en la cintura (García Barrios y Vázquez 2011: 60). Corte es el término que usan los grupos mayas actuales de los Altos de Guatemala.
} 
En el siglo VII, el diseño fue modificado por las mujeres de Calakmul y aquellas bajo su influencia: el traje de dos piezas cambió a una túnica o huipil con el cinturón de xook y la concha (García Barrios y Vázquez 2011: 66). Esta nueva tradición del traje de red está muy vinculada a las estelas pareadas y aparece en ciudades asociadas a la hegemonía Kanu'l. A partir de c. 623 (Estela 28 de Calakmul) hasta mediados del siglo VIII, diferentes y muy importantes mujeres fueron representadas con este atavío en varias partes del área maya (Figuras 4a y 4b). En el Clásico Tardío, el atavío de red estilo Kanu'l, i.e. la túnica o huipil, se encuentra en el sur de las Tierras Bajas, en el Petén oriental y en la región del Petexbatun, en sitios claramente vinculados a la esfera Kanu'l, i.e. Calakmul, La Corona, Uxul, El Perú, Naachtun, Naranjo, Cancuen y Dos Pilas, así como con otros posibles aliados como Itzimte y El Chorro (Cuadro 2, Figura 4b).

Debido a la coincidencia en la distribución de la túnica y el sistema hegemónico Kanu'l, este atavío refleja el establecimiento de relaciones maritales o maternas, u otro tipo de pactos y alianzas con los gobernantes de Calakmul. 32 apariciones (de 55) -excluyendo los ejemplos de Cobá y Xultun- datan del periodo entre 623 y 736 , y parecen estar estrechamente ligadas al establecimiento del asiento de poder de los Kanu'l en Calakmul (Helmke y Awe 2016a, 2016b; Martin y Velásquez 2016; Stuart 2012). Sólo siete ejemplos corresponden al Clásico Temprano (entre 400/450 y 600) (Figura 6a), 4 o $5^{9}$ casos son más tardíos de 750 (Cuadro 2). No obstante, la túnica de red no era la única variante en uso, pues también tenemos mujeres vistiendo el atavío de dos piezas que no había desaparecido del todo (Figura 4b, p. ej. Panel 10 de Dos Pilas, estelas 29 y 31 de Naranjo). En el Clásico Tardío, la distribución del traje de red dibuja un muro imaginario alrededor de Tikal, que recuerda el patrón visto en la distribución de las estelas pareadas (Figuras 4 y 6). El Panel 10 de Dos Pilas es uno de los ejemplos más tardíos (c. 750) de una mujer con el traje de red (Houston 1987: 302). Los Mutu'l de Dos Pilas y los Kanu'l de Calakmul establecieron una relación cercana y leal, y Dos Pilas fue un aliado de los Kanu'l hasta el final de su gloria. Esta relación también explica el uso del traje de red por la Señora Seis Cielo de Dos Pilas que gobernó Naranjo. Los ejemplos de esta reina vistiendo el traje de red incluyen las estelas 3, 24, 29 y 31 cubriendo un rango temporal que va de 702 a 721 (Cuadro 2). Como se mencionó al inicio, los lazos de parentesco con los Kanu'l están bien documentados en los monumentos de La Corona, en particular los matrimonios entre las ixkanu'l ajaw -hijas de los gobernantes Kanu'l-y el linaje local. Los matrimonios entre la hija de Ch'e'n, con el gobernante de El Perú no es clara en el registro epigráfico, pero es implícita dada la referencia de su nombre y el vínculo con el gobernante en las estelas pareadas 33 y 34 .

Casos poco claros son los de Naachtun, Itzimte y El Chorro. En Naachtun, por lo menos una ixkanu'l ajaw erigió un monumento, Estela 10 (Morley 1937: láminas 41d-e, 151e). Además, la Estela 18 del mismo sitio menciona el topónimo de Calakmul, Uxte' Tuun, probablemente haciendo referencia al lugar de humillación de un cautivo (Alfonso Lacadena, comunicación personal citada en García Barrios y Vázquez 2012: 110). Itzimte podría haber estado bajo la influencia Kanu'l, considerando que a escasos kilómetros se encuentra Zapote Bobal, un aparente vasallo de Calakmul. El Chorro pudo haber estado bajo el control de los Mutu'l de Dos Pilas,

\footnotetext{
La imprecisión se debe a que los textos no son legibles y el fechamiento obedece al estilo gráfico y contexto arqueológico.
} 
uno de los aliados más importantes de los Kanu'l. Su participación en la tradición de la túnica de red también se observa en la Estela de San Francisco, donde una ixmutu'l ajaw viste dicho atuendo.

El uso del traje de red en Palenque se inició después de las guerras con los Kanu'l y aparece asociado a la madre de Janaab Pakal, a Pakal y a su esposa en el Tablero Oval del Palacio, la Tapa del Sarcófago, el Tablero del Templo XIV y el del Palacio, en 683,654, c. 700 y 720 , respectivamente. Estos ejemplos nos recuerdan la posibilidad de que Janaab Pakal pudiera haber sido impuesto como gobernante por los Kanu'l, después de la derrota de Palenque (Stuart y Stuart 2008: 150). En las siguientes décadas, y posiblemente influenciado por la tradición palencana, el traje de red se comenzó a distribuir en las Tierras Bajas mayas occidentales, apareciendo en sitios como Pomoná, Moral Reforma, Xupá y Pomoy.

La relación entre Cobá y la dinastía Kanu'l es poco clara. Llama la atención que la Estela 1 de Cobá menciona la fecha 9.12.10.5.12, 4 Eb 10 Yax (27 de agosto de 682), que también aparece en las estelas 24 y 29 de Naranjo haciendo referencia a la llegada de la Señora Seis Cielo, hija de Bajlaj Chan K'awiil de Dos Pilas, a Naranjo a reinstaurar la autoridad política (Thompson 1932; Reese-Taylor et al. 2009: 49, 54, 61). Stuart (2010: 3-4) considera que la mención de la misma fecha en los monumentos de Cobá y Naranjo no es una coincidencia sino «an important historical connection between» ambas entidades, ya que la llegada de la Señora Seis Cielo a Naranjo fue un evento crucial de gran importancia histórica e implicaciones políticas para la compleja red de alianzas construida por los Kanu'l. Dicha fecha cae dentro del gobierno de Ch'e'n, quien llevó a la dinastía a su época de mayor influencia, expandiendo su dominio de una manera sin precedente. Sin embargo, la interacción entre Cobá y Calakmul es poco entendida ya que parece haber pistas para una alianza entre Cobá y Tikal en contra de Calakmul (Esparza 2016: 291-294).

\subsection{Los paneles de los jugadores de pelota}

Como han observado Christophe Helmke y colegas (2015), otro patrón visual promovido ampliamente por los Kanu'l es la representación de los jugadores de pelota en tableros de escalinatas jeroglíficas (Cuadro 3, Figura 5). En estas escenas, los gobernantes Kanu'l aparecen con otros individuos, que frecuentemente se identifican a través de los textos jeroglíficos como gobernantes locales de los sitios de los que proceden dichos tableros. Monumentos relevantes que contienen información sobre la afiliación con los Kanu'l vienen de La Corona (Stuart et al. 2015b), El Perú (Lee 2012; Lee y Piehl 2014: 95-98), Uxul (Grube et al. 2012; Grube y Delvendahl 2013, 2014), El Palmar (Tsukamoto et al. 2015), Dos Pilas (Houston 1993) y Zapote Bobal (Tunesi 2007) (Figura 5). Todos estos sitios son bien conocidos por haber formado parte de la red sociopolítica Kanu'l durante el Clásico Tardío, tras el establecimiento de su sede de poder en Calakmul. Los textos en los tableros de Toniná también parecen expresar una alianza con los Kanu'l (Stuart 2013), mientras que las apariciones más tardías en Yaxchilán (Graham y von Euw 1982: 155, 164), Quirigua (Crasborn et al. 2012) y Cobá (Benavides 1976; Mayer 1988; Esparza 2016: 83-84) son menos obvias, aunque la evidencia epigráfica disponible hoy día apunta a la posible existencia de alianzas contemporáneas o más tempranas en los tres casos. Basados en este patrón, Helmke y sus colegas (2015) proponen que también Tipan Chen Uitz, con sus tableros recientemente descubiertos, perteneció a la red de alianzas, aunque su 
Cuadro 3. Paneles de jugadores de pelota. (EJ: escalinata jeroglífica)

\begin{tabular}{|c|c|c|c|c|c|}
\hline Sitio & Monumento & Fecha & Estructura & $\begin{array}{l}\text { Gobernante } \\
\text { asociado }^{i}\end{array}$ & Referencia \\
\hline Uxul & Altar 2 & c. 642 & $\begin{array}{l}\text { Sur de Es- } \\
\text { tructura F1 }\end{array}$ & $\begin{array}{l}\text { (El mismo que en } \\
\text { Panel 2, Escalina- } \\
\text { ta Norte) }\end{array}$ & $\begin{array}{l}\text { (Ruppert y Denison } \\
\text { 1943; Grube y Delven- } \\
\text { dahl 2013: 66) }\end{array}$ \\
\hline Uxul & Panel 1 & $652-705$ & $\begin{array}{l}\text { K2, Escalina- } \\
\text { ta Sur }\end{array}$ & $\begin{array}{l}\text { Nombre destruido } \\
\text { K'uhul Kanu'l } \\
\text { Ajaw }\end{array}$ & $\begin{array}{l}\text { Representación de } \\
\text { jugador y texto corto } \\
\text { (Grube et al. 2012: 34; } \\
\text { Grube y Delvendahl } \\
\text { 2013: 64) }\end{array}$ \\
\hline Uxul & Panel 2 & ¿636-686? & $\begin{array}{l}\text { K2, Escalina- } \\
\text { ta Sur }\end{array}$ & ¿Ch'e'n II? & $\begin{array}{l}\text { Representación de } \\
\text { jugador y texto corto } \\
\text { (Grube et al. } 2012: 34 \text {; } \\
\text { Grube y Delvendahl } \\
\text { 2013: 67, 2014: } 91-92 \text { ) }\end{array}$ \\
\hline Uxul & Panel 1 & $652-705$ & $\begin{array}{l}\mathrm{K} 2 \text {, Escalina- } \\
\text { ta Norte }\end{array}$ & $\begin{array}{l}\text { Nombre destruido } \\
\text { K'uhul Kanu'l } \\
\text { Ajaw }\end{array}$ & $\begin{array}{l}\text { Representación de } \\
\text { jugador y texto corto } \\
\text { (Grube et al. 2012: } 34 \text { ) }\end{array}$ \\
\hline La Corona & Elemento 13 & 662 & $?$ & $\begin{array}{l}\text { Chak Ak' Paat } \\
\text { Kuy (Yihch'aak } \\
\text { K'ahk') }\end{array}$ & (Stuart et al. 2015a: 9) \\
\hline Uxul & Panel 4 & 695 & $\begin{array}{l}\text { K2, Escalina- } \\
\text { ta Sur }\end{array}$ & $\begin{array}{l}\text { Yihch'aak K'ahk' } \\
\text { (gobernante de } \\
\text { Uxul: Muyal } \\
\text { Chaak) }\end{array}$ & $\begin{array}{l}\text { Representación de } \\
\text { jugador y texto corto } \\
\text { (Grube et al. 2012: } 34 \text {; } \\
\text { Grube y Delvendahl } \\
\text { 2013: 68-69, 2014) }\end{array}$ \\
\hline Yaxchilán & EJ 2 & Finales s. VII & Estructura 33 & $\begin{array}{l}\text { (Yaxuun Bahlam } \\
\text { IV) }\end{array}$ & $\begin{array}{l}\text { (Graham y von Euw } \\
\text { 1982:155-164) }\end{array}$ \\
\hline Calakmul & Elemento 39 & $\begin{array}{l}\text { c. } 700 \text { (re- } \\
\text { trospectiva) } \\
\text { (contexto } \\
\text { secundario) }\end{array}$ & $\begin{array}{l}\text { Estructura } \\
\text { XIII }\end{array}$ & Ch'e'n II & (Martin 2012: 160) \\
\hline $\begin{array}{l}\text { Tipan Chen } \\
\text { Uitz }\end{array}$ & $\begin{array}{l}\text { Monumen- } \\
\text { to } 4\end{array}$ & $\begin{array}{l}711 \text { (contexto } \\
\text { secundario) }\end{array}$ & $\begin{array}{l}\text { Estructura } \\
\text { A-1 }\end{array}$ & $\begin{array}{l}\text { Janaab Chanal } \\
\text { K'ahk' (NAR) }\end{array}$ & (Helmke et al. 2015) \\
\hline $\begin{array}{l}\text { Tipan Chen } \\
\text { Uitz }\end{array}$ & $\begin{array}{l}\text { Monumen- } \\
\text { to } 3\end{array}$ & $\begin{array}{l}716 \text { (contexto } \\
\text { secundario) }\end{array}$ & $\begin{array}{l}\text { Estructura } \\
\text { A-1 }\end{array}$ & $\begin{array}{l}\text { «Ocelote Voluta } \\
\text { de Agua» }\end{array}$ & $\begin{array}{l}\text { (Helmke et al. 2015: } \\
\text { 16) }\end{array}$ \\
\hline Dos Pilas & EJ 1 & 724 & EJ 1 & $\begin{array}{l}\text { Kokaaj K'awiil } \\
\text { (Gobernante 2) }\end{array}$ & $\begin{array}{l}\text { (Houston 1993: 110, } \\
\text { Fig. 3-22.) }\end{array}$ \\
\hline El Palmar & Bloque II & 726 & $\begin{array}{l}\text { EJ, Grupo } \\
\text { Guzmán }\end{array}$ & erosionado & $\begin{array}{l}\text { (Tsukamoto et al. } \\
\text { 2015) }\end{array}$ \\
\hline Toniná & $\begin{array}{l}\text { Monumento } \\
171\end{array}$ & $\begin{array}{l}727 \text { (contexto } \\
\text { secundario) }\end{array}$ & Acrópolis & $\begin{array}{l}\text { ¿K'ihnich } \\
\text { Yihch'aak? Cha- } \\
\text { paht }\end{array}$ & (Stuart 2013) \\
\hline $\begin{array}{l}\text { Zapote } \\
\text { Bobal }\end{array}$ & Panel & c. $736-744$ & $\begin{array}{l}\text { Colección } \\
\text { privada }\end{array}$ & $\begin{array}{l}\text { Wamaaw K'awiil, } \\
\text { Kalo'mte', } \\
\text { Janaab Ti' O', } \\
\text { ¿K'uhul? ¿? Ajaw }\end{array}$ & $\begin{array}{l}\text { (Tunesi 2007) } \\
\text { Glifo Emblema de } \\
\text { Kanu'l }\end{array}$ \\
\hline
\end{tabular}




\begin{tabular}{|c|c|c|c|c|c|}
\hline Yaxchilán & $\begin{array}{l}\text { Bloque X, } \\
\text { EJ } 2\end{array}$ & c. 751 & Estructura 33 & $\begin{array}{l}\text { K'an Tok Wayaab } \\
\text { (Yaxuun Bahlam } \\
\text { IV) }\end{array}$ & $\begin{array}{l}\text { (Graham y von Euw } \\
\text { 1982: 155-164) }\end{array}$ \\
\hline Quirigua & $\begin{array}{l}\text { Panel de jue- } \\
\text { go de pelota } \\
\text { de la Banca } \\
\text { Oeste }\end{array}$ & c. 808 & $\begin{array}{l}\text { Estructura } \\
\text { IB-14 }\end{array}$ & $\begin{array}{l}\text { K'ahk' Jolow } \\
\text { Chan Yopaat }\end{array}$ & (Crasborn et al. 2012) \\
\hline Cobá & $\begin{array}{l}\text { EJ Escultu- } \\
\text { ra } 1\end{array}$ & $\begin{array}{l}\text { Clásico Tar- } \\
\text { dío } \\
\text { (contexto } \\
\text { secundario) }\end{array}$ & $\begin{array}{l}\text { Estructura } \\
\text { 33, Grupo D }\end{array}$ & Erosionado & $\begin{array}{l}\text { (Benavides 1976; } \\
\text { Mayer 1988; Esparza } \\
\text { 2016: 83-84) }\end{array}$ \\
\hline Cobá & $\begin{array}{l}\text { EJ Escultu- } \\
\text { ra } 2\end{array}$ & $\begin{array}{l}\text { Clásico Tar- } \\
\text { dío } \\
\text { (contexto } \\
\text { secundario) }\end{array}$ & Sacbe 1 & Erosionado & $\begin{array}{l}\text { (Benavides 1976; } \\
\text { Mayer 1988; Esparza } \\
\text { 2016: 83-84) }\end{array}$ \\
\hline El Perú & $\begin{array}{l}\text { Tablero del } \\
\text { jugador de } \\
\text { pelota ( } 3 \\
\text { fragmentos) }\end{array}$ & $\begin{array}{l}\text { Clásico } \\
\text { Terminal } \\
\text { (contexto } \\
\text { secundario) }\end{array}$ & EJ 2, Palacio & $\begin{array}{l}\text { Yihch'aak K'ahk' } \\
\text { ¿K'ihnich Bahlam } \\
\text { II? }\end{array}$ & $\begin{array}{l}\text { (Lee 2012; Lee y Piehl } \\
\text { 2014: 95-98) }\end{array}$ \\
\hline
\end{tabular}

${ }^{\mathrm{i}}$ Se usan comillas cuando se trata de un sobrenombre.

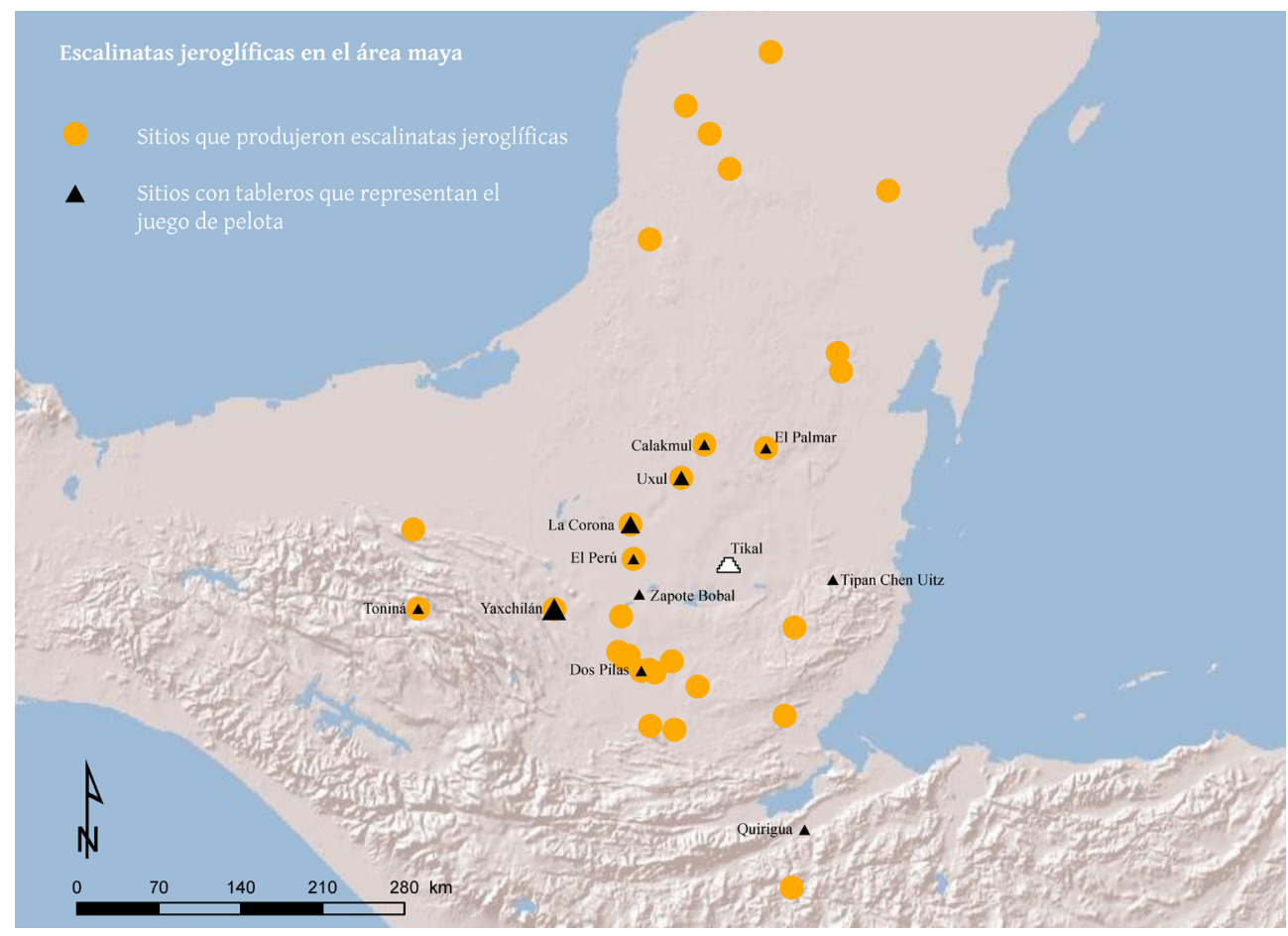

Figura 5. Distribución de escalinatas jeroglíficas y paneles de jugadores de pelota en el área maya (mapa realizado por Felix Kupprat y Verónica A. Vázquez López, basado en Helmke et al. 2015). 
relación con Calakmul pudo ser indirecta, a través de Naranjo (Helmke et al. 2015: 21). Este tipo de representaciones en sitios estrechamente vinculados a la dinastía Kanu'l, sugiere que no sólo tenían el fin de representar el juego per se, sino también expresar alianzas o pactos sociopolíticos entre ambas unidades, como marcadores simbólicos que fomentaron las relaciones de lealtad y realzaron el poder, la posición y el prestigio del gobernante subordinado (ver también Helmke et al. 2015).

\section{Discusión}

Los cánones visuales compartidos en estelas pareadas, monumentos donde se representa el traje de red y paneles de jugadores de pelota aquí discutidos, junto con su distribución en las Tierras Bajas mayas y sus fechas, reflejan el desarrollo de un programa iconográfico que formó parte de un discurso hegemónico. Los sitios que reprodujeron estos medios visuales fueron miembros de una red poderosa al mando de la dinastía Kanu'l. La producción de monumentos que no sólo comparten un estilo específico sino también una base simbólica, etiquetó a los gobernantes participantes como miembros de un sistema de alianzas y vasallaje ${ }^{10}$ Kanu'l. Estos repertorios compartidos también reflejan una política y, posiblemente, una ideología compartida, pues todos los patrones están estrechamente ligados a las insignias de poder político. Sería difícil entender sus implicaciones políticas sólo mirando a la evidencia iconográfica, por lo que el dato epigráfico es una fuente invaluable para la reconstrucción del sistema sociopolítico. Es sencillo inferir que los sitios que comparten un patrón iconográfico de alguna manera están relacionados entre sí por parentesco, matrimonio u otro tipo de vínculos; que comparten tradiciones y prácticas, o que eran parte de una red política, pero sería difícil definir la naturaleza de estas relaciones. La evidencia epigráfica, por otro lado, ofrece información más precisa sobre el tipo de lazos -relaciones parentales, matrimonios, relaciones maternas, vasallaje, tipos de subordinación, etc.-, sobre dinámicas sociopolíticas -títulos, oficios, jerarquías- y sobre rituales, ceremonias y mitos.

En combinación, imagen, texto y dato arqueológico ofrecen indicadores sobre distintos tipos de alianzas o pactos como parte de un sistema de estrategias de reproducción sociopolítica desarrollado por los Kanu'l. La distribución de estelas pareadas, mujeres con el traje de red en el Clásico Tardío y los paneles de jugadores de pelota confirman la visión de una red fuerte construida por los Kanu'l, abarcando un área vasta del mundo maya, al tiempo que enfatiza la preocupación de los Kanu'l de aislar a Tikal, neutralizando su poder mediante el establecimiento de alianzas con sitios ubicados en sus alrededores, construyendo un muro imaginario cercando a su rival y su zona inmediata de influencia (Figura 6).

Las estrategias sociopolíticas fueron importantes en el proceso activo de legitimación. A través de ellas se reforzaron las relaciones pues funcionaron como declaraciones de jerarquía social y política (ver Tokovinine 2016). Los matrimonios que establecieron los Kanu'l con otras unidades sociales funcionaron como una fuente

\footnotetext{
${ }^{10}$ Por vasallaje entiendo una relación de subordinación pactada entre dos partes, donde una tiene mayor rango y poder político que la otra. En este tipo de alianza, ambas partes obtienen obligaciones y beneficios. El vasallo se comprometía a ofrecer cierto tipo de apoyo militar, político o económico a cambio de beneficios que le hicieran mantener su posición y poder, incluso de protección militar, política o económica en una esfera más amplia.
} 


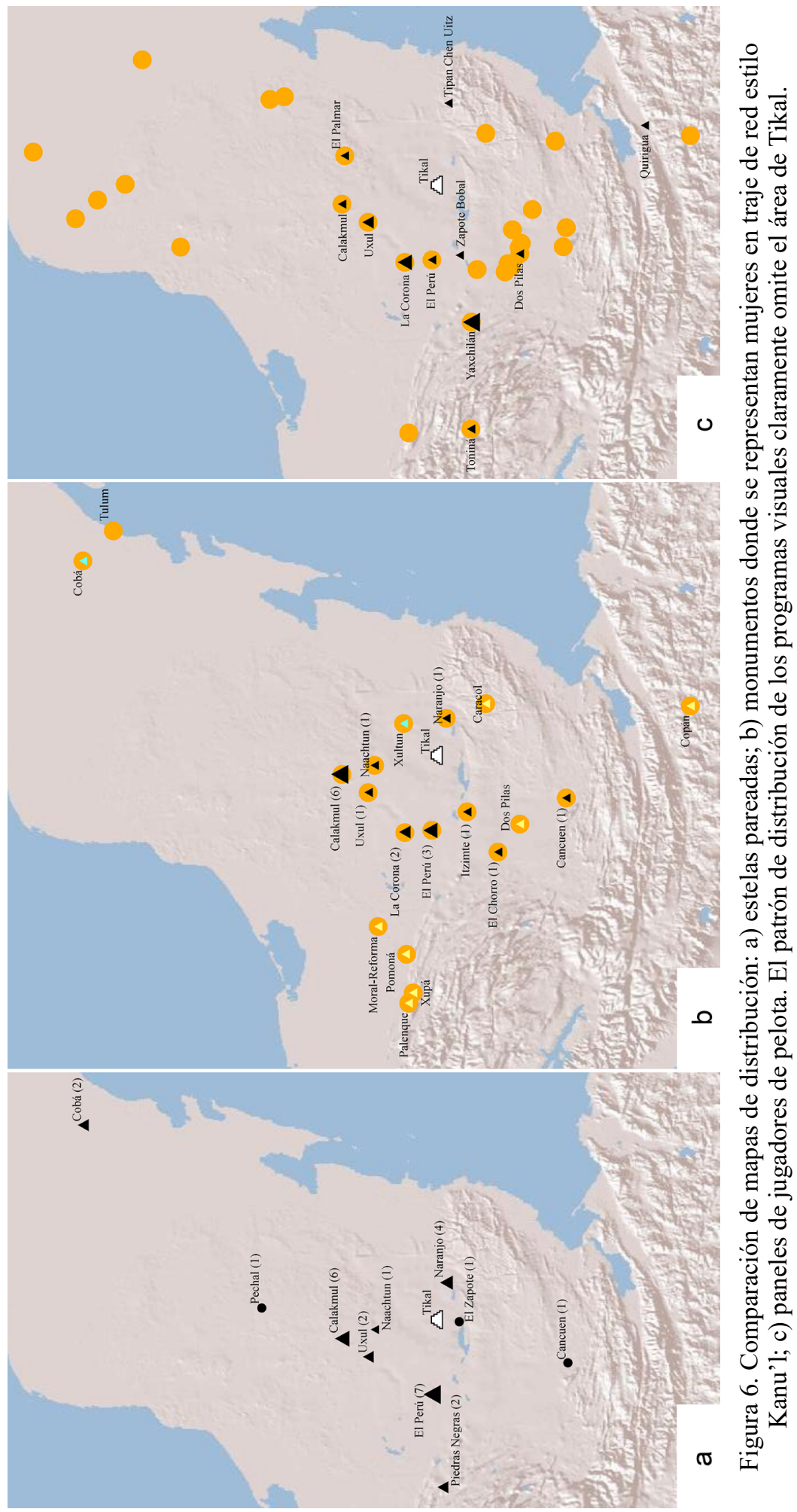


de vida externa ofreciendo la posibilidad de expandir su influencia al exterior. Estas alianzas implicaron la transferencia de estatus, bienes materiales y autoridad política de un patrilinaje a otro, a través de mujeres miembros de casas de mayor rango social. Como indica Marilyn Strathern (1984), el intercambio de matrimonios en su doble sentido se refiere al flujo de uniones entre las unidades sociales, así como a otras transacciones que acompañan al matrimonio. Las estrategias mencionadas aquí pudieron facilitar intercambios generalizados a largo plazo, como se refleja entre los Kanu'l y las unidades sociales de La Corona y los Mutu'l de Dos Pilas, cuyos vínculos perduraron hasta después de la caída de Ti' K'awiil. Este tipo de vínculos entre dos patrilinajes crearon alianzas y pactos que dieron apoyo social, militar y económico, mediante la creación y mantenimiento de redes sociopolíticas.

Mientras hay evidencia textual y visual sobre las alianzas matrimoniales en La Corona y El Perú, aún carecemos de evidencia de matrimonios intersitio en Uxul. Sin embargo, los bloques de jugadores de pelota en Uxul confirman los lazos políticos con los Kanu'l, junto con expresiones de supervisión y el arreglo arquitectónico del núcleo de la ciudad que se asemeja al de Calakmul (Grube y Delvendahl 2013, 2014). Uxul está tan cerca de Calakmul, c. $34 \mathrm{~km}$, que formó parte del área de influencia inmediata de los Kanu'l (Grube 2005, 2008; Grube et al. 2012; Grube y Delvendahl 2013, 2014). También tenemos casos en que los Kanu'l actuaron como intermediarios, sancionando matrimonios y otros pactos políticos, como vimos con el caso de la Señora Seis Cielo de Dos Pilas enviada a Naranjo y en el ejemplo de los paneles de jugadores de pelota de Tipan Chen Uitz.

Además de la importancia de las alianzas políticas y económicas, otras estrategias también fueron determinantes en la reproducción del sistema político. La guerra y el control de recursos fueron tácticas comunes para la subyugación. Estrategias que ayudaron a establecer lazos a voluntad -o por lo menos la ilusión de ésta-incluyeron matrimonios, pactos consolidados mediante el juego de pelota, bailes, banquetes (ver Tokovinine 2016) y el intercambio de regalos y dones. Otras estrategias se enfocaron en el reconocimiento social de comunidades integradas (ver Baron 2013, 2016). Mecanismos de cohesión social se emplearon no sólo a larga distancia sino también a nivel interno como se observa en la incorporación de estelas de distintos linajes en el programa arquitectónico del Clásico Tardío de Calakmul, cuando los Kanu'l integraron las estelas 43 y 114 -erigidas por un chatahn winik y un k'uhul suutz ajaw, respectivamente- en la fachada de la Estructura II, otorgando respeto a estos linajes subordinados (ver Vázquez et al. 2016).

Es importante señalar que la evidencia revela varios niveles de integración y participación de los Kanu'l en los asuntos de sus aliados y vasallos (Vázquez 2015; también discutido en Grube y Delvendahl 2014). El grado de influencia en una comunidad no era el mismo en sitios cercanos a Calakmul que en aquellos más lejanos como Caracol, El Perú, Cancuen o Quirigua, donde los gobernantes Kanu'l debieron tener un papel menos activo (también ver Helmke et al. 2015). Sitios más cercanos a la zona inmediata de influencia de Calakmul, como Uxul, vivieron una mayor y más directa influencia o afectación, lo cual se refleja no sólo en los códigos visuales o el arreglo espacial, sino también en el relativo rápido abandono del sitio después de la caída de los Kanu'l (Vázquez 2015: 305-317). El último monumento de Uxul se erigió en 705, y el análisis cerámico muestra un rápido decrecimiento de la población, aunque el abandono total no ocurrió antes del 750 (Dzul Góngora y Bach 2013; Grube y Delvendahl 2013: 73). Por su parte, la información arqueológica y cerámica 
muestra que La Corona y El Perú se mantuvieron activos por más tiempo. La Corona -c. $90 \mathrm{~km}$ de Calakmul- parece haber sido abandonado alrededor de 850 (Canuto y Barrientos 2009; Baron 2013; Barrientos y Canuto 2014: 14; Barrientos et al. 2015: 13-15, 477), a pesar del vínculo especial entre ambas casas sociales. El Perú $-c$. $115 \mathrm{~km}$ de Calakmul, $25 \mathrm{~km}$ de La Corona y $75 \mathrm{~km}$ de Tikal- tiene una ubicación peculiar, más cercano a Tikal pero con lazos fuertes con Calakmul durante el Clásico Tardío. El arreglo espacial del sitio es más complejo que el de Uxul y La Corona, y su ocupación también es más larga, siendo abandonado alrededor del 1000 (Eppich 2011: 32-43). Esta ocupación más larga indica un nivel más alto de independencia, mientras que su cercanía con Tikal explica su interacción con ese sitio después de la caída de Kanu'l. Aparentemente, Tikal se centró en integrar a los antiguos vasallos de los Kanu'l a su esfera adoptando la misma estrategia del matrimonio hipogámico. El Monumento 6 de La Corona (805), p. ej., muestra a una mujer con el glifo emblema de Mutu'l que llegó a La Corona en 791 (Baron 2013: 334). Algo parecido puede haber sucedido en Itzimte, cuyos gobernantes parecen haber mantenido lazos con Tikal en el Clásico Temprano, posiblemente con los Kanu'l en el siglo VII y con Motul de San José a partir de la segunda mitad del siglo VIII (Beliaev et al. 2017). En El Perú no tenemos evidencia de un matrimonio con Tikal, quizá debido a que Tikal atacó este sitio en 743 según el Dintel del Templo IV de Tikal (Guenter 2014a: 161). Estos casos demuestran los distintos grados de integración que se encontraban incluso en sitios relativamente centrales dentro de la esfera Kanu'l, sugiriendo que la distancia a la capital regional era un factor clave para el control y la influencia.

Agradecimientos. Gracias a Ana García Barrios por su complicidad e inspiración que dieron origen a este trabajo, y que junto con Daniel Salazar Lama me invitaron a participar en esta publicación e hicieron comentarios y observaciones a la misma. Agradezco profundamente a Christophe Helmke, Chloé Andrieu, Harri Kettunen y Erik Velásquez por sus comentarios, observaciones y guía en mi doctorado. A Felix Kupprat por sus comentarios, sugerencias y por la generación de mapas. A Beniamino Volta, Kai Delvendahl y Nikolai Grube por su invitación al simposio Las estrategias hegemónicas de la dinastía Kaan en el marco del Congreso Internacional de Mayistas, 2016, donde expuse una versión preliminar de este trabajo. Gracias también al evaluador de este artículo por sus comentarios. Gracias al CONACyT y su programa de becas «Apoyo para Estancias Posdoctorales en el Extranjero Vinculadas a la Consolidación de Grupos de Investigación y Fortalecimiento del Posgrado Nacional 2018 (1)».

\section{Referencias}

Baron, Joanne Parsley. 2013. Patrons of La Corona: Deities and Power in a Classic Maya Community. Tesis Doctoral. Department of Anthropology, University of Pennsylvania. 2016. Patron Gods and Patron Lords. The Semiotics of Classic Maya Community Cults. Boulder: University Press of Colorado.

Barrientos Quezada, Tomás y Marcello A. Canuto. 2014. «Proyecto Regional Arqueológico La Corona: Objetivos y antecedentes de la temporada 2013», en Proyecto Arqueológico La Corona: Informe final, Temporada 2013, Tomás Barrientos, Marcello A. Canuto y Jocelyn Ponce, eds., pp. 1-10. Informe entregado al Instituto de Antropología e Historia de Guatemala.

Barrientos Quezada, Tomás, Marcello A. Canuto y José E. Bustamante. 2015. Proyecto Arqueológico La Corona. Informe Final Temporada 2014. Informe entregado al Instituto de Antropología e Historia de Guatemala. 
Baudez, Claude-Françoise. 1994. Maya Sculpture of Copán: The Iconography. Norman: University of Oklahoma Press.

Beliaev, Dmitri, Philipp Galeev, Sergie Vepretski, Camilo Luin y Alejandro Garay. 2017. «Development of a Classic Maya Secondary Polity at Itzimte». Ponencia presentada en la $82^{\circ}$ Annual SAA Meeting. Vancouver.

Beliaev, Dmitri, Alexandre Tokovinine, Sergio Vepretskiy y Camilo Luin. 2013. «Los monumentos de Tikal», en Informe Final No. 1: Temporada abril-mayo 2013. Proyecto Atlas Epigráfico de Petén, Fase I, Dmitri Beliaev y Mónica de León, eds., pp. 37-170. Informe presentado a la Dirección General de Patrimonio Cultural y Natural y al Departamento de Monumentos Prehispánicos y Coloniales. Guatemala.

Benavides Castillo, Antonio. 1976. «Cobá, Quintana Roo, reporte de actividades», en Cobá: Un sitio maya en Quintana Roo, pp. 1-104. México: Instituto Nacional de Antropología e Historia, Dirección de Centros Regionales.

Canuto Marcello A. y Tomás Barrientos Quezada. 2009. Proyecto Arqueológico La Corona. Informe Final Temporada 2008. Informe entregado al Instituto de Antropología e Historia de Guatemala

Carrasco Vargas, Ramón, Sylviane Boucher, Claude Baudez, Jean Pierre Courau, Anne Dowd, Marc Wolf, Emily González, Simon Martin, Valeria García, Renata Schneider, Gloria Sánchez, Rosalía Carrillo, Armando Paul, Nidia Rojas y Melissa Brook. 1996. Proyecto Arqueológico de la Biosfera de Calakmul Temporada 1993-1994. Informe entregado al Instituto Nacional de Antropología e Historia, México.

Carrasco Vargas, Ramón, Sylviane Boucher, Emily González, Yoly Palomo, Paula Álvarez González, Vera Tiesler, Sara Dzul y Renata García Moreno. 1997. Proyecto arqueológico Calakmul. Informe de los trabajos arqueológicos, Temporada 1996-1997. Informe entregado al Instituto Nacional de Antropología e Historia, México.

Crasborn, José, Elizabeth Marroquín, Federico Fahsen y Ma. Elena Vega. 2012. «Un nuevo monumento en Quirigua: La banca y panel tallados de la Estructura 1B-14 del Grupo Este», en XXV Simposio de Investigaciones Arqueológicas en Guatemala 2011, Bárbara Arroyo, Luis Paiz y Héctor Mejía, eds., pp. 387-401. Guatemala: Museo Nacional de Arqueología y Etnología.

Dzul Góngora, Sara y Julia Bach. 2013. «La cerámica de Uxul: Lo local, lo regional y lo ajeno». Ponencia presentada en el $9^{\circ}$ Congreso Internacional de Mayistas. Campeche.

Eppich, Keith. 2011. Lineage and State at El Perú-Waka': Ceramic and Architectural Prespectives on the Classic Maya Social Dynamic. Tesis Doctoral. Department of Anthropology, Southern Methodist University.

Esparza Olguín, Octavio Quetzalcóatl. 2016. Estudio de los monumentos esculpidos de Cobá, Quintana Roo, y su contexto arqueológico. Tesis Doctoral. Postgrado en Estudios Mesoamericanos, Universidad Nacional Autónoma de México.

Euw, Eric von e Ian Graham. 1984. Corpus of Maya Hieroglyphic Inscriptions, Vol. 5, Part 2: Xultun. Cambridge: Peabody Museum of Archaeology and Ethnology, Harvard University.

García Barrios, Ana y Verónica A. Vázquez López. 2011. «The Weaving of Power: Women’s Clothing and Protocol in the Seventh-Century Kingdom of Kanu'l». Latin American Indian Literatures Journal 27 (1): 50-95.

- 2012. «Moda y protocolo femenino en el reino de Kanu'l (siglo VII d.C.)», en Maya Daily Lives, Philippe Nondédéo y Alain Breton, eds., pp. 95-116. Markt Schwaben: Verlag Anton Saurwein.

García Moll, Roberto. 2005. Pomoná: Un sitio del Clásico maya en las colinas tabasqueñas. México: Instituto Nacional de Antropología e Historia. 
García Moreno Rodríguez, Renata. 2001. Les coiffures funeraires de Calakmul, Campeche, Mexique. Leur etude technologique et symbolique. Tesis Doctoral. Département d'Archéologie de l'Amérique Précolombienne, Université Paris I Panthéon-Sorbonne.

Garza, Mercedes de la, Guillermo Bernal Romero y Martha Cuevas García. 2012. PalenqueLakamha': Una presencia inmortal del pasado indígena. México: Fondo de Cultura Económica, El Colegio de México, Fideicomiso Historia de las Américas.

Gómez Palacios, Ricardo. En prensa. «Los tocados mayas en el discurso político. Un estudio de caso de los tocados de serpiente acuática durante el Clásico Tardío». Estudios de la Cultura Maya 55.

Graham, Ian. 1978. Corpus of Maya Hieroglyphic Inscriptions, Vol. 2, Part 2: Naranjo. Cambridge: Peabody Museum of Archaeology and Ethnology, Harvard University.

Graham, Ian y Eric von Euw. 1975. Corpus of Maya Hieroglyphic Inscriptions, Vol. 2, Part 1: Naranjo. Cambridge: Peabody Museum of Archaeology and Ethnology, Harvard University.

- 1982. Corpus of Maya Hieroglyphic Inscriptions, Vol. 3, Part 1: Yaxchilán. Cambridge: Peabody Museum of Archaeology and Ethnology, Harvard University.

- 1997. Corpus of Maya Hieroglyphic Inscriptions, Vol. 8, Part 1: Coba. Cambridge: Peabody Museum of Archaeology and Ethnology, Harvard University.

Grube, Nikolai. 1994. «Epigraphic Research at Caracol, Belize», en Studies in the Archaeology of Caracol, Belize, Monograph 7, Diana Z. Chase y Arlen F. Chase, eds., pp. 83112. San Francisco: Pre-Columbian Art Research Institute.

. 2005. «Toponyms, Emblem Glyphs, and the Political Geography of Southern Campeche». Anthropological Notebooks 11: 89-102.

- 2008. «Monumentos esculpidos: epigrafía e iconografía», en Reconocimiento arqueológico en el sureste de Campeche, Ivan Šprajc, ed., pp. 177-231. BAR International Series 1742. Oxford: Archaeopress.

Grube, Nikolai y Kai Delvendahl. 2013. «Nuevos hallazgos en el conjunto palaciego de Uxul», en Los Investigadores de la Cultura Maya 21, Tomo II, pp. 57-90. Campeche: Universidad Autónoma de Campeche.

- 2014. «The Monuments of the Ajaw 8 House: New Evidence on the Calakmul-Uxul Relationship», en $A$ Celebration of the Life and Work of Pierre Robert Colas, Christophe Helmke y Frauke Sachse, eds., pp. 75-95. Acta Mesoamericana 27. Munich: Verlag Anton Saurwein.

Grube, Nikolai, Kai Delvendahl, Nicolaus Seefeld y Beniamino Volta. 2012. «Under the Rule of the Snake Kings: Uxul in the 7th and 8th centuries». Estudios de Cultura Maya 40: 11-49.

Guenter, Stanley P. 2005. «Informe preliminar de la epigrafia de El Perú», en Proyecto Arqueológico El Peru-Waka': Informe No. 2, Temporada 2004, Héctor L. Escobedo y David A. Freidel, eds., pp. 363-400. Informe entregado al Instituto de Antropología e Historia de Guatemala.

- 2014a. «The Epigraphy of El Perú», en Archaeology at El Perú-Waka'. Ancient Maya Performances of Ritual, Memory, and Power, Olivia C. Navarro-Farr y Michelle Rich, eds., pp. 147-167. Tucson: The University of Arizona Press.

- 2014b. «The Queen of Cobá: A Reanalysis of the Macanxoc Stelae», en The Archaeology of Yucatán, Travis W. Stanton, ed., pp. 395-422. Oxford: Archaeopress.

Hellmuth, Nicholas M. 1987. Monster und Menschen in der Maya-Kunst: Eine Ikonographie der alten Religionen Mexikos und Guatemalas. Graz: Akademische Druck- u. Verlagsanstalt. 
Helmke, Christophe. 2016. «Indicators of Matrilocality and Maternal Dominance during the Regency of Lady Six Sky at Naranjo, Guatemala». Ponencia presentada en el $5^{\text {th }}$ European Maya Conference, Wayeb. Jagiellonian University, Cracovia.

Helmke, Christophe y Jaime J. Awe. 2016a. «Death Becomes Her: An Analysis of Panel 3, Xunantunich, Belize». The PARI Journal 16 (4): 1-14.

- 2016b. «Sharper than a Serpent's tooth: A Tale of the Snake-head Dynasty as Recounted on Xunantunich Panel 4». The PARI Journal 17 (2): 1-22.

Helmke, Christophe, Christopher R. Andres, Shawn G. Morton y Gabriel D. Wrobel. 2015. «For Love of the Game: The Ballplayer Panels of Tipan Chen Uitz in Light of Late Classic Athletic Hegemony». The PARI Journal 16 (2): 1-30.

Houston, Stephen D. 1986. «Problematic Emblem Glyphs: Examples from Altar de Sacrificios, El Chorro, Río Azul and Xultun». Research Reports in Ancient Maya Writing 3: 1-11.

-1987. «Notes on Caracol Epigraphy and Its Significance», en Investigations at the Classic Maya City of Caracol, Belize 1985-1987, Arlen D. Chase y Diane Z. Chase, eds., pp. 85-100. San Francisco: Pre-Columbian Art Research Institute.

- 1993. Hieroglyphs and History at Dos Pilas: Dynastic Politics of the Classic Maya. Austin: University of Texas Press.

-1998. «Classic Maya Depictions of the Built Environment», en Function and Meaning in Classic Maya Architecture, Stephen D. Houston, ed., pp. 333-372. Washington, D.C.: Dumbarton Oaks Research Library and Collection.

Houston, Stephen D. y David Stuart. 2001. «Peopling the Classic Maya Court», en Royal Courts of the Ancient Maya. Volume One: Theory, Comparison, and Synthesis, Takeshi Inomata y Stephen D. Houston, eds., pp. 54-83. Boulder: Westview Press.

Jabłońska, Asia. 2016. «Iconography and style of Calakmul's imperialism imposed on its hinterlands in the Late Classic Period». Ponencia presentada en $21^{\text {st }}$ European Maya Conference, Wayeb. Moscú.

Jackson, Sarah E. 2005. Deciphering Classic Maya Political Hierarchy: Epigraphic, Archaeological, and Ethnohistoric Perspectives on the Courtly Elite. Tesis Doctoral. Department of Anthropology, Harvard University.

2013. Politics of the Maya Court. Hierarchy and Change in the Late Classic Period. Norman: University of Oklahoma Press.

Jones, Christopher y Linton Satterthwaite. 1982. The Monuments and Inscriptions of Tikal. Filadelfia: University Museum, University of Pennsylvania.

Joyce, Rosemary A. 2000. Gender and Power in Prehispanic Mesoamerica. Austin: University of Texas Press.

Le Fort, Geneviève. 2002. «El traje real entre los mayas de la época clásica (250-900 d. C.)», en Actas de las II Jornadas Internacionales sobre Textiles Precolombinos, Victoria Solanilla, ed., pp. 27-41. Barcelona: Universidad Autónoma de Barcelona.

Lee, David F. 2012. Approaching the End: Maya Royal Ritual in the Palace Group at El Perú-Waka', Petén Guatemala. Tesis Doctoral. Department of Anthropology, Southern Methodist University.

Lee, David F. y Jennifer C. Piehl. 2014. «Ritual and Remembrance at the Northwest Palace Complex, El Perú-Waka'», en Archaeology at El Perú-Waka'. Ancient Maya Performances of Ritual, Memory, and Power, Olivia C. Navarro-Farr y Michelle Rich, eds., pp. 85-101. Tucson: The University of Arizona Press.

Looper, Matthew G. 2002. «Women-Men (and Men-Women): Classic Maya Rules and the Third Gender», en Ancient Maya Women, Traci Ardren, ed., pp. 171-202. Walnut Creek: Altamira Press. 
Maler, Teobert. 1901. Researches in the Central Portion of the Usumatsintla Valley. Cambridge: Peabody Museum of American Archaeology and Ethnology.

Marcus, Joyce. 1987. The Inscriptions at Calakmul: Royal Marriage at a Maya City in Campeche, Mexico. Technical Report 21. Ann Arbor: University of Michigan Museum of Anthropology.

- 1992. Mesoamerican Writing Systems. Propaganda, Myth, and History in Four Ancient Civilizations. Princeton: Princeton University Press.

- 2006. «Identifying Elites and their Strategies», en Intermediate Elites in Pre-Columbian States and Empires, Christina M. Elson y R. Alan Covey, eds., pp. 212-246. Tucson: University of Arizona Press.

Martin, Simon. 1998. «Investigación Epigráfica de Campo: 1995-1998», en Informe Técnico, Proyecto Arqueológico Calakmul, Ramón Carrasco Vargas et al., pp. 72-122. Informe entregado al Instituto Nacional de Antropología e Historia, México.

- 2004. «Preguntas epigráficas de los escalones de Dzibanché», en Los cautivos de Dzibanché, Enrique Nalda Hernández, ed., pp. 105-116. México: Instituto Nacional de Antropología e Historia.

- 2005. «Of Snakes an Bats: Shifting Idintities at Calakmul». The PARI Journal 6 (2): 5-13. . 2008. «Wives and Daughters on the Dallas Altar». Mesoweb. http://www.mesoweb. com/articles/martin/Wives\&Daughters.pdf.

- 2012. «Escritura», en Calakmul. Patrimonio de la Humanidad, Regina Martínez Vera, ed., pp. 157-175. México: Grupo Azabache.

Martin, Simon y Nikolai Grube. 1995. «Maya Superstates». Archaeology 48 (6): 41-46.

- 2008. Chronicle of the Maya Kings and Queens: Deciphering the Dynasties of the Ancient Maya. 2a. edición. Londres: Thames and Hudson.

Martin, Simon y David Stuart. 2009. «The Snake Kingdom. History and Politics at Calakmul and Related Royal Courts». 2009 Maya Meetings Sourcebook. Austin: University of Texas.

Martin, Simon y Erik Velásquez García. 2016. «Polities and Places: Tracing the Toponyms of the Snake Dynasty». The PARI Journal 17 (2): 23-33.

Mathews, Peter y Alexander Parmington. 2005. «Investigaciones epigráficas (Operación 6)», en Proyecto Arqueológico Naachtun: Informe No. 1, Febrero-Abril de 2004, Martin Rangel y Kathrine Reese-Taylor, eds., pp. 104-113. Informe entregado al Instituto de Antropología e Historia de Guatemala.

Mayer, Karl H. 1988. «Ein Maya Ballspielerrelief aus Coba, Quintana Roo, Mexiko». Ethnologia Americana 113: 1203-1205.

Mejía, Héctor E., José Miguel García Campillo y Juan Pedro Laporte. 2005. «La Estela 6 de Itzimté, Petén, Guatemala». Mexicon XXVII (2-3): 37-40.

Miller, Virginia E. 1981. Pose and Gesture in Classic Maya Monumental Sculpture. Tesis Doctoral. Department of Art and Art History, University of Texas.

- 1983. «A Reexamination of Maya Gestures of Submission». Journal of Latin American Lore 9 (1): 17-38.

Montgomery, John. 2000. The Montgomery Drawings Collection. FAMSI. http://research. famsi.org/montgomery.html.

Morley, Sylvanus Griswold. 1937. The Inscriptions of Petén. Washington, D.C.: Carnegie Institution of Washington.

Nalda Hernández, Enrique. 2004. «Dzibanché: El contexto de los cautivos», en Los cautivos de Dzibanché, Enrique Nalda Hernández, ed., pp. 13-56. México: Instituto Nacional de Antropología e Historia. 
Proskouriakoff, Tatiana. 1961. «Portraits of Women in Maya Art», en Essays in Pre-Columbian Art and Archaeology, Samuel K. Lothrop et al., eds., pp. 81-89. Cambridge: Harvard University Press.

Quenon, Michel y Geneviève Le Fort. 1997 «Rebirth and Resurrection in Maize God Iconography», en The Maya Vase Book, Volume 5, Barbara y Justin Kerr, eds., pp. 884-902. Nueva York: Kerr Associates.

Reese-Taylor, Kathryn, Peter Mathews, Julia Guernsey y Marlene Fritzler. 2009. «Warrior Queens among the Classic Maya», en Blood and Beauty: Organized Violence in the Art and Archaeology of Mesoamerica and Central America, Heather Orr y Rex Koontz, eds., pp. 39-72. Los Angeles: Cotsen Institute of Archaeology, University of California.

Ruppert, Karl y John H. Denison. 1943. Archaeological Reconnaissance in Campeche, Quintana Roo, and Peten. Washington, D.C.: Carnegie Institution of Washington.

Schele, Linda. 1986. «Architectural Development and Political History at Palenque», en City-States of the Maya: Art and Architecture, Elizabeth P. Benson, ed., pp. 110-137. Denver: Rocky Mountain Institute for Pre-Columbian Studies.

Schele, Linda y Peter Mathews. 1998. The Code of Kings: The Language of Seven Sacred Maya Temples and Tombs. Nueva York: Touchstone.

Schele, Linda, Federico Fahsen y Nikolai Grube. 1992. «El Zapote and the dynasty of Tikal». Texas Notes 34.

Stewart, Daniel Maroni. 2009. Parentage Statements and Paired Stelae: Signs of Dynastic Succession for the Classic Maya. Tesis de Maestría. Department of Anthropology, Brigham Young University.

Strathern, Marilyn. 1984. «Marriage Exchanges: A Melanesian Comment». Annual Review of Anthropology 13: 41-73.

Stuart, David. 1998. "'The Fire Enters His House': Architecture and Ritual in Classic Maya Texts», en Function and Meaning in Classic Maya Architecture, Stephen D. Houston, ed., pp. 373-425. Washington, D.C.: Dumbarton Oaks Research Library and Collection.

- 2010. «Notes on Accession Dates in the Inscriptions of Cobá», en David Stuart's Notes, Mesoweb. http://www.mesoweb.com/stuart/notes/Coba.pdf.

- 2012. «Notes on a New Text from La Corona», Maya Decipherment: Ideas on Ancient Maya Writing and Iconography. Blog, David Stuart, ed. https://decipherment. wordpress.com/2012/06/30/notes-on-a-new-text-from-la-corona/.

_. 2013. «Tonina's Curious Ballgame», Maya Decipherment: Ideas on Ancient Maya Writing and Iconography. Blog, David Stuart, ed. https://decipherment.wordpress. com/2013/06/11/report-toninas-curious-ballgame/.

—. 2014. «Reconstructing a Stucco Text from Palenque's Palace», en Maya Decipherment: Ideas on Ancient Maya Writing and Iconography. Blog, David Stuart, ed. https:// decipherment.wordpress.com/2014/07/15/reconstructing-a-stucco-text-from-palenquespalace/.

Stuart, David y George Stuart. 2008. Palenque: Eternal City of The Maya. Londres: Thames and Hudson.

Stuart, David, Marcello A. Canuto y Tomás Barrientos Quezada. 2015a. «The Nomenclature of La Corona Sculpture». La Corona Notes 1 (2): 1-9.

Stuart, David, Marcello A. Canuto, Tomás Barrientos Quezada, Jocelyn Ponce Stokvis y Joanne Baron. 2015b. «Death of the Defeated: New Historical Data on Block 4 of La Corona's Hieroglyphic Stairway 2». La Corona Notes 1 (3): 1-7.

Taube, Karl A. 1992. The Major Gods of Ancient Yucatan. Washington D.C.: Dumbarton Oaks Research Library and Collection. 
Taube, Karl A. y Stephen D. Houston. 2015. «Masks and Iconography», en Temple of the Night Sun. A Royal Tomb at El Diablo, Guatemala, Stephen D. Houston, Sarah Newman, Edwin Román y Thomas Garrison, eds., pp. 208-229. San Francisco: Precolumbian Mesoweb Press.

Thompson, J. Eric S. 1932. «Monuments of the Cobá Region», en A Preliminary Study of the Ruins of Cobá, Quintana Roo, Mexico, pp. 131-184. Washington, D. C.: Carnegie Institution of Washington.

Tokovinine, Alexander. 2016. «It is his Image with Pulque: Drinks, Gifts, and Political Networking in Classic Maya Texts and Images». Ancient Mesoamerica 27 (1): 13-29.

Tsukamoto, Kenichiro, Javier López Camacho, Luz Evelia Campaña Valenzuela, Hirokazu Kotegawa y Octavio Q. Esparza Olguín. 2015. «Political Interactions among Social Actors: Spatial Organization at the Classic Maya Polity of El Palmar, Campeche, Mexico». Latin American Antiquity 26 (2): 200-220.

Tunesi, Raphael. 2007. «A New Monument Naming Wamaaw K'awiil of Calakmul». The PARI Journal 8 (2): 13-19.

Vázquez López, Verónica A. 2011. El parentesco dentro de la estructura política de los mayas del Clásico: Un acercamiento epigráfico y lexicográfico al caso del señorío de Kaan[V]l. Tesis de Maestría. Posgrado en Estudios Mesoamericanos, Universidad Nacional Autónoma de México.

2014. «Social Units in the Sociopolitical Structure of the Late Classic Maya: The Case of the Kanu'l Dynasty», en Sociopolitical Strategies among the Maya from the Classic Period to the Present, Verónica A. Vázquez, Rogelio Valencia y Eugenia Gutiérrez, eds., pp. 127-157. BAR International Series 2619. Oxford: Archaeopress.

- 2015. Dinastías, linajes y casas: Las unidades sociales mayas en el ámbito político de los Kanu'l en el Clásico Tardío. Tesis Doctoral. Posgrado en Estudios Mesoamericanos, Universidad Nacional Autónoma de México.

Vázquez López, Verónica A. y Felix Kupprat. 2018. «Pertenencia y transmisión de nombres entre los Kanu'l en el Clásico Tardío». Estudios de Cultura Maya 51: 75-110.

Vázquez López, Verónica A., Felix Kupprat, Carlos Morales Aguilar, Hugo García Capistrán y Rogelio Valencia Rivera. 2016. «Los cambios de poder en el juego interdinástico: los gobernantes de Calakmul de los siglos V a VIII d.C.», en XXIX Simposio de Investigaciones Arqueológicas en Guatemala 2015, Bárbara Arroyo, Luis Méndez Salinas y Gloria Ajú Álvarez, eds., pp. 1101-1114. Guatemala: Museo Nacional de Arqueología y Etnología.

Velásquez García, Erik. 2004. «Los escalones jeroglíficos de Dzibanché», en Los cautivos de Dzibanché, Enrique Nalda Hernández, ed., pp. 79-105. México: Instituto Nacional de Antropología e Historia.

. 2009. Los vasos de la entidad política de 'Ik': Una aproximación histórico-artística. Estudio sobre las entidades anímicas y el lenguaje gestual y corporal en el arte maya clásico. Tesis Doctoral. Historia del Arte, Universidad Nacional Autónoma de México. 